Received: 19 April 2018

Accepted: 4 July 2018

Published online: 24 July 2018

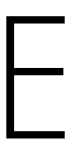

C N
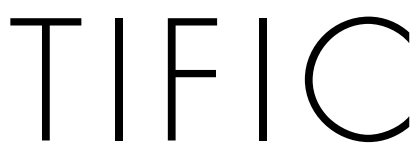

REP

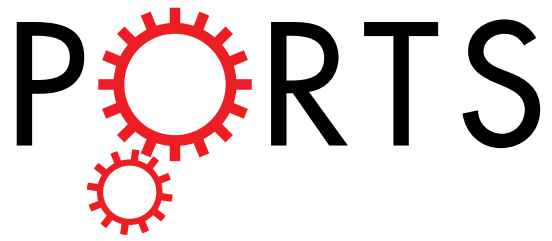

\title{
OPEN
}

\section{Inhibition of Tunneling Nanotube (TNT) Formation and Human T-cell Leukemia Virus Type 1 (HTLV-1) Transmission by Cytarabine}

Maria Omsland ${ }^{1,2}$, Cynthia Pise-Masison ${ }^{2}$, Dai Fujikawa², Veronica Galli ${ }^{2}$, Claudio Fenizia $\mathbb{1}^{2,3}$, Robyn Washington Parks ${ }^{2}$, Bjørn Tore Gjertsen $\mathbb{1}^{1,4}$, Genoveffa Franchini ${ }^{2}$ \& Vibeke Andresen ${ }^{1,4}$

The human T-cell leukemia virus type 1 (HTLV-1) is highly dependent on cell-to-cell interaction for transmission and productive infection. Cell-to-cell interactions through the virological synapse, biofilm-like structures and cellular conduits have been reported, but the relative contribution of each mechanism on HTLV-1 transmission still remains vastly unknown. The HTLV-1 protein p8 has been found to increase viral transmission and cellular conduits. Here we show that HTLV-1 expressing cells are interconnected by tunneling nanotubes (TNTs) defined as thin structures containing F-actin and lack of tubulin connecting two cells. TNTs connected HTLV-1 expressing cells and uninfected T-cells and monocytes and the viral proteins Tax and Gag localized to these TNTs. The HTLV-1 expressing protein p8 was found to induce TNT formation. Treatment of MT-2 cells with the nucleoside analog cytarabine (cytosine arabinoside, AraC) reduced number of TNTs and furthermore reduced TNT formation induced by the $\mathrm{p} 8$ protein. Intercellular transmission of HTLV-1 through TNTs provides a means of escape from recognition by the immune system. Cytarabine could represent a novel anti-HTLV-1 drug interfering with viral transmission.

Worldwide, it is estimated that at least 5-10 million people are infected with human T-cell leukemia virus type-1 (HTLV-1), the first human oncogenic retrovirus discovered ${ }^{1-4}$. While most infected individuals remain life-long asymptomatic carriers, after a latency of several decades, approximately 3-5\% develops an aggressive adult T-cell leukemia/lymphoma (ATL) and 1-4\% a neurodegenerative condition HTLV-1 associated myelopathy (HAM)/ tropical spastic paraparesis (TSP) ${ }^{1-6}$. HTLV-1 infections have additionally been associated with inflammatory conditions such as uveitis, bronchoalveolitis and arthritis, Sjögrens syndrome and polymyostis ${ }^{7-10}$.

In vivo, HTLV-1 has been found in different cell types such as $\mathrm{CD} 4^{+} \mathrm{T}$-cells, $\mathrm{CD} 8^{+} \mathrm{T}$-cells, dendritic cells, macrophages, B-cells, endothelial cells and monocytes ${ }^{11-21}$. However, only CD4 ${ }^{+}$memory T-cells undergo HTLV1 -dependent cellular transformation and is therefore considered the main cellular target of this virus ${ }^{22,23}$. For viral infection, Glucose Transporter 1 (GLUT1), Heparan Sulfate Proteoglycans (HSPG) and Neuropilin 1 (NRP-1) have been identified as the HTLV-1 receptor complex important for viral binding and cellular entry ${ }^{24,25}$. However, in contrast to HIV-1, cell-free HTLV-1 particles in the plasma of HTLV-1 infected individuals are almost undetectable and, except in dendritic cells, cell-free infections are very inefficient ${ }^{26}$. Therefore cell-to-cell contacts are considered the main and most efficient method of HTLV-1 transmission and spread ${ }^{26-29}$. Thus, mechanisms to reduce cell-to-cell transmission have the potential to significantly reduce viral burden. Two different cell-to-cell contacts have been described in HTLV-1 transmission. The virological synapse (VS) is defined as a virus induced tight cell-to-cell interaction creating a synaptic intercellular cleft allowing viral budding and transmission. This causes a viral induced polarization of the microtubule-organizing center (MTOC) in the donor cell towards the virological synapse $\mathrm{s}^{30,31}$. Viral biofilms, consisting of extracellular matrix and lectins, have been discovered on the

${ }^{1}$ Centre for Cancer Biomarkers (CCBIO), Precision Oncology Research Group, Department of Clinical Science, University of Bergen, Bergen, Norway. ${ }^{2}$ Animal Models and Retroviral Vaccines Section, Vaccine Branch, National Cancer Institute, National Institutes of Health, Bethesda, Maryland, USA. ${ }^{3}$ Department of Pathophysiology and Transplantation, University of Milan, Milan, Italy. ${ }^{4}$ Department of Internal Medicine, Haukeland University Hospital, Bergen, Norway. Correspondence and requests for materials should be addressed to V.A. (email: vibeke.andresen@ uib.no) 
surface of HTLV-1 infected cell lines ${ }^{32}$. The HTLV-1 particles are concentrated and protected by the biofilms and transmitted to the target cell ${ }^{32}$. For long distance cell-to-cell interactions we previously reported viral transmission in T-cells by cellular conduits, a process enhanced by the HTLV-1 encoded protein $\mathrm{p} 8^{33,34}$. The $\mathrm{p} 8$ protein is generated by a two-step proteolytic cleavage of the 12 protein $^{33}$, encoded by open reading frame 1 (orf- $I$ ) in the HTLV-1 genome, previously demonstrated to be involved in viral persistence ${ }^{35-37}$. First, p12 is cleaved between amino acids in position 9 and 10 and then between amino acids 29 and 30, where the nature of the amino acids surrounding these cleavage sites determines the efficiency of cleavage and polymorphism has been found in HTLV-1 infected individuals ${ }^{33,36}$. Interestingly, also the $\mathrm{p} 8$ protein itself is transferred through cellular conduits to neighboring cells ${ }^{34,38}$. Transmission of HTLV-1 through these types of cell-to-cell contacts could provide protection from recognition by the immune system ${ }^{34}$.

In the present study, we further examined long-distance cell-to-cell interactions utilized by HTLV-1 expressing T-cells and found that these infected cells form tunneling nanotubes (TNTs), often containing the viral proteins Tax and Gag, between T-cells as well as monocytes. TNTs are thin (50-200 nm in diameter) and long $(5-100 \mu \mathrm{m})$ cell-to-cell interconnecting structures lacking contact with the substratum, embedded by plasma membrane containing filamentous actin (F-actin) ${ }^{39}$. A variety of immune cells interact through TNTs including natural killer (NK) cells, macrophages, T-cells and B-cells ${ }^{40-42}$. TNTs have also been reported in HIV-1 infected T-cells and macrophages, in influenza A infected cells and cells infected by bovine herpesvirus $1^{43-48}$. In a recent study we demonstrated that the pyrimidine nucleoside analog cytarabine reduced NF- $\kappa$ B activation and TNT formation in acute myeloid leukemia (AML) cells ${ }^{49}$. Here we find that cytarabine treatment also resulted in reduced number of TNTs in HTLV-1 cells. In MT-2 cells, cytarabine reduced expression of Tax, Gag and viral production and caused a decrease in viral transmission from MT- 2 cells as well as primary HTLV- 1 infected CD $4^{+}$cells to uninfected cells. By sequencing of orf-I in the HTLV-1 infected cell lines included in this study we found that the MT-2 cells, demonstrating the highest amount of TNTs, contained the orf-I isoform N26, earlier demonstrated to express mostly the 88 protein $^{36}$. Expression of orf-I-N26 (p8) in Jurkat cells enhanced TNT formation whereas cytarabine treatment reduced TNT numbers, however, not influencing $\mathrm{p} 8$ expression. Thus, our work shows that cytarabine could have possible therapeutic effects to reduce HTLV-1 transmission by reduced communication of HTLV-1 infected cells with uninfected cells.

\section{Results}

HTLV-1 expressing cells form tunneling nanotubes (TNTs). We previously reported the presence of cellular conduits in HTLV-1 expressing cells ${ }^{34}$. At that time these structures did not fulfil the strict criteria of being a TNT and were consequently named cellular conduits ${ }^{34}$. Since HIV-1 has been shown to facilitate TNTs for viral spread between T-cells and macrophages ${ }^{43,44,48}$ we wanted to determine if HTLV-1 infected cells formed TNTs as well. The definition of a TNT in the present study is; a thin $(200 \mathrm{~nm}$ in diameter, $>5 \mu \mathrm{m}$ length $)$ membrane embedded, actin-containing, tubulin absent, structure interconnecting two cells simultaneously hovering above the surface of the well. Cytoplasmic bridges, the TNT-like structures following cell division, were excluded through the characteristic mid-body ${ }^{48,49}$. TNTs are very fragile structures in vitro, and thus, cellular fixation; in particular of suspension cells that are semi-adherent to fibronectin coated surfaces, will result in TNT breakage . $^{50}$. Hence, suspension cells are generally analysed by live cell microscopy. However, because MT-2 cells produce infectious HTLV-1 viral particles ${ }^{51,52}$, they require fixation before analysis by confocal microscopy in regular microscopy core facilities. Thin intercellular connections $>5 \mu \mathrm{m}$ were found in the MT- 2 cells (Fig. 1A). These connections did not adhere to the plastic surface and contained F-actin, but no $\alpha$-tubulin and therefore qualified, according to the TNT definition, as TNTs (Fig. 1B). To further analyse the TNTs in more detail, we performed scanning electron microscopy (SEM). In the MT-2 cells, TNTs hovering above the substratum were found interconnecting cells and interestingly, at one end only, a branched anchoring was frequently observed (Fig. 1C, arrows) as also described for other cellular systems ${ }^{53}$. Furthermore, knob-like structures were observed in the TNTs (Fig. 1C, ii, arrowheads) which could indicate transport of cargo through these structures as previously described ${ }^{54}$.

The HTLV-1 infected cell lines C91PL (HTLV-1 producing), C8166 (no viral production, but expression of Tax protein), two ATL-derived T-cell lines TL-Om1 and ATL-ED (no viral production or Tax expression) and the HTLV-1-negative cell lines Jurkat (T-cells), CEM (T-cells) and THP-1 (monocytes) where further compared to MT-2 cells with respect to TNT forming capabilities. All HTLV-1 transformed cell lines were fixed and stained with WGA-Alexa488 prior to analysis by microscopy, whereas the HTLV-1-negative cell lines were analysed by live cell imaging. In order to visualize TNTs without the need of cellular staining, Jurkat and THP-1 cells were stably transduced with memGFP or memCherry, respectively, (see material and methods) to directly visualize TNTs and distinguish the originating cell (Fig. 2A). To compare TNT formation in the different cell lines, TNTs/100 cells were quantified as described earlier ${ }^{49}$. MT-2 cells consistently formed more TNTs when compared to the other HTLV-1 positive cells (Fig. 2B). TNT formation in MT-2 cells was similar to that quantified of unfixed THP-1 and CEM cells and since fixation will reduce the number of TNTs as stated above, and demonstrated by comparing fixation of CEM cells resulted in a $60.9 \%(\mathrm{p}<0.0065)$ reduction in detectable TNTs (Fig. 2B), it is likely that the TNT numbers in unfixed MT-2 cells will be higher.

HTLV-1 expressing cells form TNTs with non-infected T-cells and monocytes containing Tax and Gag. To further investigate the TNT connections between HTLV-1 positive and HTLV-1 negative cells, MT- 2 cells were co-cultured with Jurkat or THP-1 cells. These cultures were compared to co-cultures of uninfected Jurkat and THP-1 cells. Firstly, in cultures of THP-1 (memGFP) and Jurkat (memCherry) cells, we found that TNTs could be generated from both cells. TNTs that originated from Jurkat cells toward THP-1 cells and vice versa were detected (data not shown). In addition, TNTs were formed that originated from both cell types simultaneously (Fig. 3A, arrows) as seen in other systems ${ }^{48}$. Further, memGFP dots were observed in the Jurkat cells 

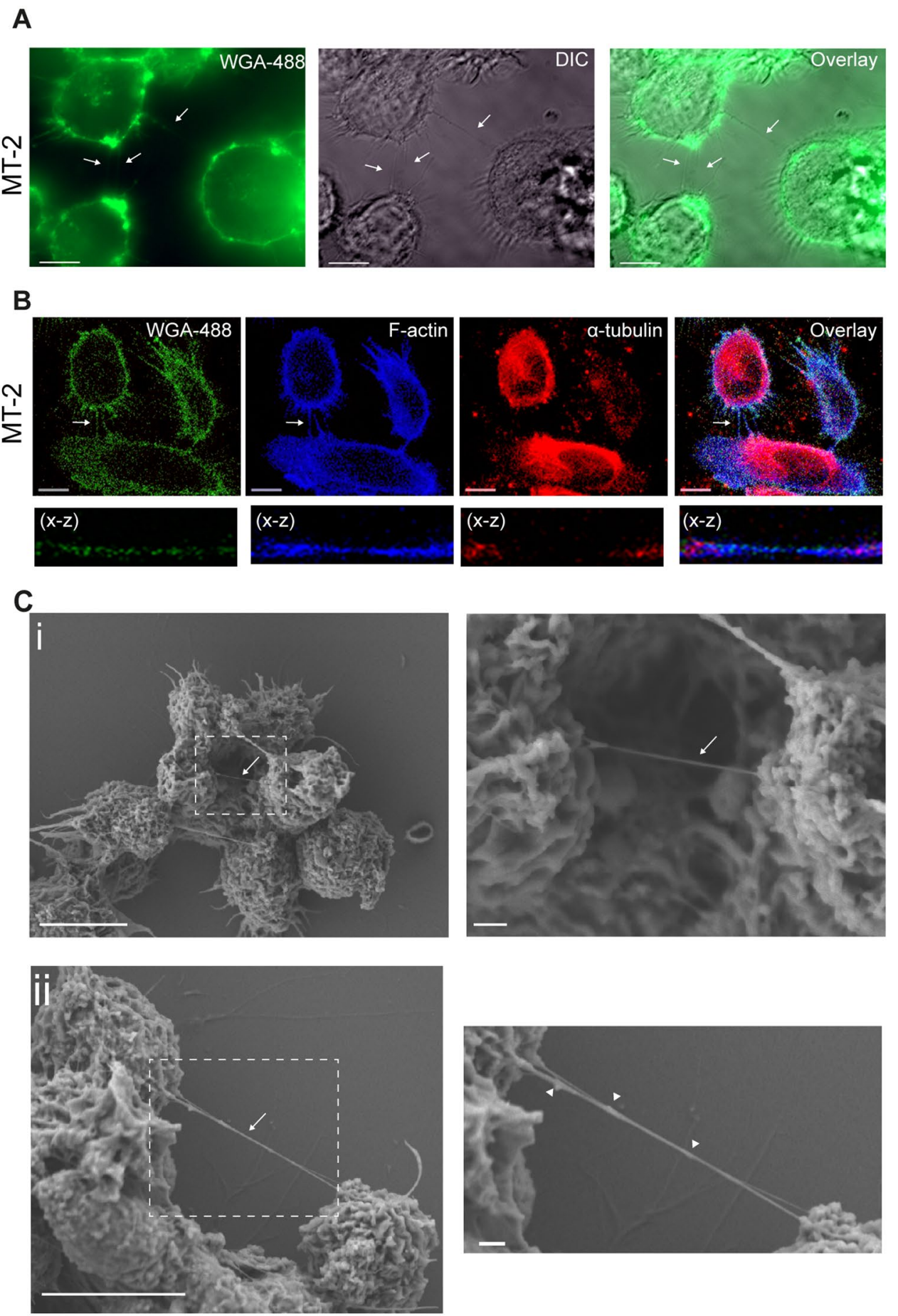

Figure 1. HTLV-1 expressing cells form tunneling nanotubes (TNTs). (A) MT-2 cells stained with WGA-488 (cellular membranes, green) and investigated by fluorescence microscopy. Arrows indicate thin membrane embedded intercellular connections. (B) MT-2 cells stained with WGA-488 (green), F-actin phalloidin-AF350 (blue) and an anti- $\alpha$-tubulin antibody (red) and analyzed by confocal microscopy. Arrows indicate a TNT. The $\mathrm{X}-\mathrm{Z}$ plane is obtained from a Z-stack (total 24 slices of $1 \mu \mathrm{m}$ each). (C) Scanning electron microscopy (SEM) of MT-2 cells connected by TNTs. Zoomed images to the right. Arrows indicate TNTs, arrowheads indicate bulges in TNTs. Images were captured by scanning electron microscope Jeol JSM-7400F LEI 4.0 kV, x3000 (x3700 for D2) and WD $8.0 \mathrm{~mm}$. Confocal microscopy images were acquired by LSM780 confocal microscope (Zeiss) and fluorescence microscopy was acquired by AxioObserver Z1 (Zeiss). All images are representatives of three independent experiments, except for (C) that was performed once. All scale bars $10 \mu \mathrm{m}$ except zoomed SEM images; $1 \mu \mathrm{m}$. Adobe photoshop CS6 was used to prepare the images. The contrast was enhanced on the whole image to better represent and visualize the thin TNT structures. 
A
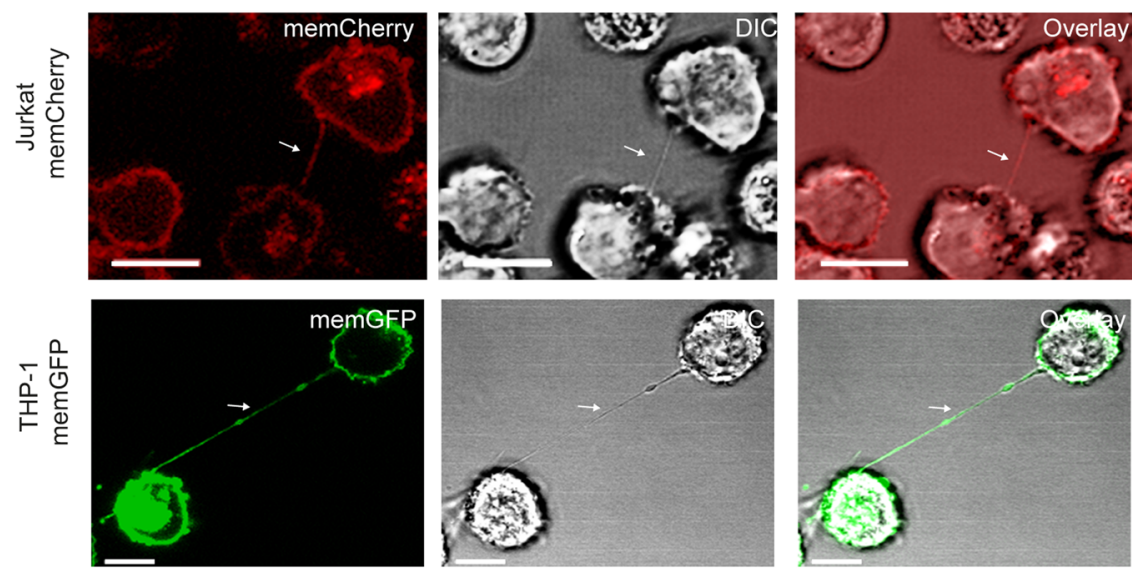

B

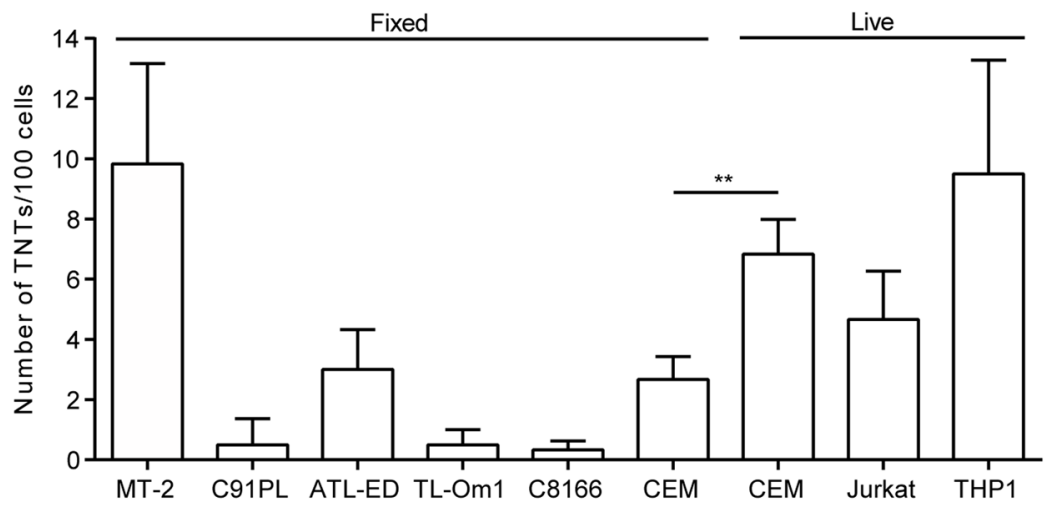

Figure 2. TNTs in HTLV-1 positive and negative cells. (A) Jurkat-memGFP (green) and THP-1-memCherry (red) cells analyzed by confocal microscopy. Arrows indicate TNTs. The images are representatives of three independent experiments. (B) TNTs were quantified in HTLV-1 transformed cells (MT-2, C91PL, ATL-ED, TLOm-1 and C8166) and in HTLV-1-negative cell lines; T-cells (CEM and Jurkat) and monocytes (THP-1). TNT quantifications in HTLV-1-negative cells were performed by live cell microscopy where the Jurkat-memCherry and THP-1-memGFP cells were directly imaged while CEM cells were stained with WGA-488 prior to imaging. All HTLV-1 transformed cells were fixed and stained with WGA- 488 before analyzed by microscopy. For the TNT quantification, 100 cells were counted in duplicate wells for the presence of TNTs connecting two cells as described earlier ${ }^{49}$. Results represent three independent experiments performed in duplicates and error bars mean \pm SD. Unpaired t-test was performed to evaluate statistical significance. F-test was performed for individual variation. GraphPad Prism (Version 6.03) was used $(* * p<0.01)$. Scale bars $10 \mu \mathrm{m}$. Adobe photoshop CS6 was used to prepare the images. The contrast was enhanced on the whole image to better represent and visualize the thin TNT structures.

possibly indicating intercellular transport from the THP-1 cells (Fig. 3A, arrowheads). When unstained MT-2 cells were co-cultured with Jurkat (memCherry) or THP-1 (memGFP) cells, TNTs were readily formed between the HTLV-1 positive and negative cells (Fig. 3B,C, arrows). When the origin of TNTs connecting MT-2 and THP- 1 cells were quantified we found that $48 \%$ of the TNTs originated from the MT- 2 cells and $52 \%$ from the THP-1 cells (Supplementary Fig. 1A) As with uninfected cells, memCherry and memGFP dots were observed in the MT-2 cells. A 3D reconstruction was made of the cells from Fig. 3C and show memGFP as well as Tax present in recipient cells (Supplementary Video 1). This suggests that membrane exchange occurs from the HTLV1-negative cells to MT-2 cells (Fig. 3B,C, arrowheads) possibly by TNTs or other mechanisms such as exosomes and phagocytosis. When the co-cultured MT-2 and THP-1 cells were immunostained for intracellular Tax protein, Tax was found localized to TNTs, and could be detected in TNTs originating from the THP-1 cells (Fig. 3D) and in TNTs generated from both MT-2 and THP-1 cells (Fig. 3E). The specificity of the immunostaining was verified by incubating mono-cultures of THP-1 (memGFP) cells with the anti-Tax antibody and in addition a Tax negative THP-1 cell is shown in a co-culture with MT-2 and THP-1 (memGFP) cells (Supplementary Fig. 1B,C). This demonstrated that HTLV-1 negative cells can generate TNTs to communicate with MT-2 cells with potential transport of membrane components and Tax protein.

Next, MT-2 cells co-cultured with THP-1 (memGFP) were immunostained for Gag. We found Gag proteins localized to the TNTs, generated by MT-2 cells towards THP-1 cells which could indicate transport of Gag from 
A
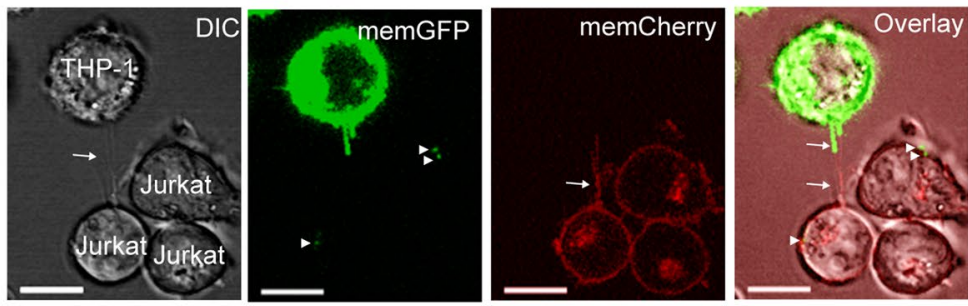

B
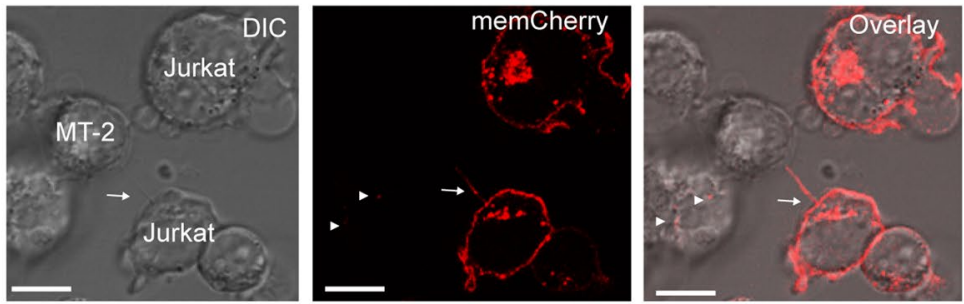

C
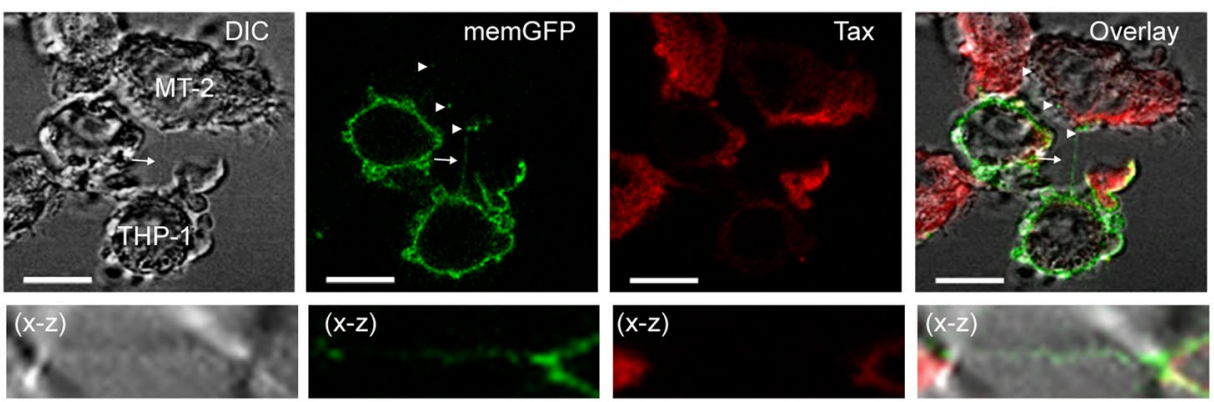

D
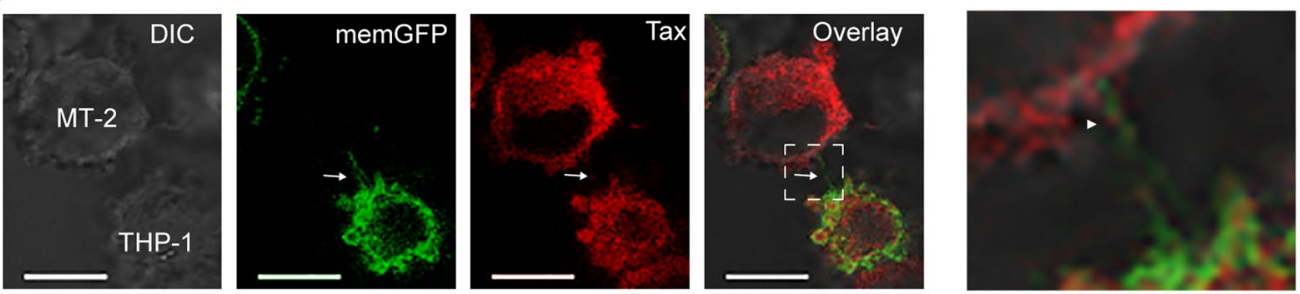

E
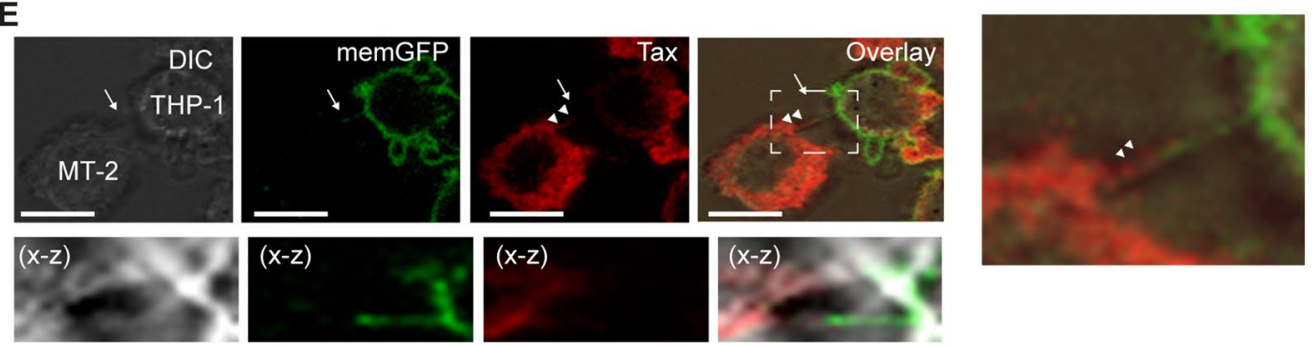

Figure 3. HTLV-1 expressing cells form TNTs with non-infected T cells and monocytes and contain Tax. (A) THP-1-memGFP and Jurkat-memCherry cells were co-cultured overnight and presence of TNTs was analyzed by DIC and fluorescent confocal microscopy. Arrows indicate TNTs and arrowheads memCherry and memGFP. (B) MT-2 (unstained) and Jurkat-memCherry cells were co-cultured overnight and the presence of TNTs was analyzed by DIC and fluorescent confocal microscopy. Arrows indicate TNTs and arrowheads memCherry. (C-E) MT-2 and THP-1-memGFP cells were co-cultured overnight and immunostained for Tax (red). The presence of TNTs was analyzed by DIC and fluorescent confocal microscopy. Arrows indicate TNTs and arrowheads memGFP (green) or Tax (red). All images are representatives of two independent experiments performed in duplicates. The X-Z plane is obtained from a Z-stack (total 32 slices of $1 \mu \mathrm{m}$ each). Scale bar $10 \mu \mathrm{m}$. Adobe photoshop CS6 was used to prepare the images. The contrast was enhanced on the whole image to better represent and visualize the thin TNT structures. 
A
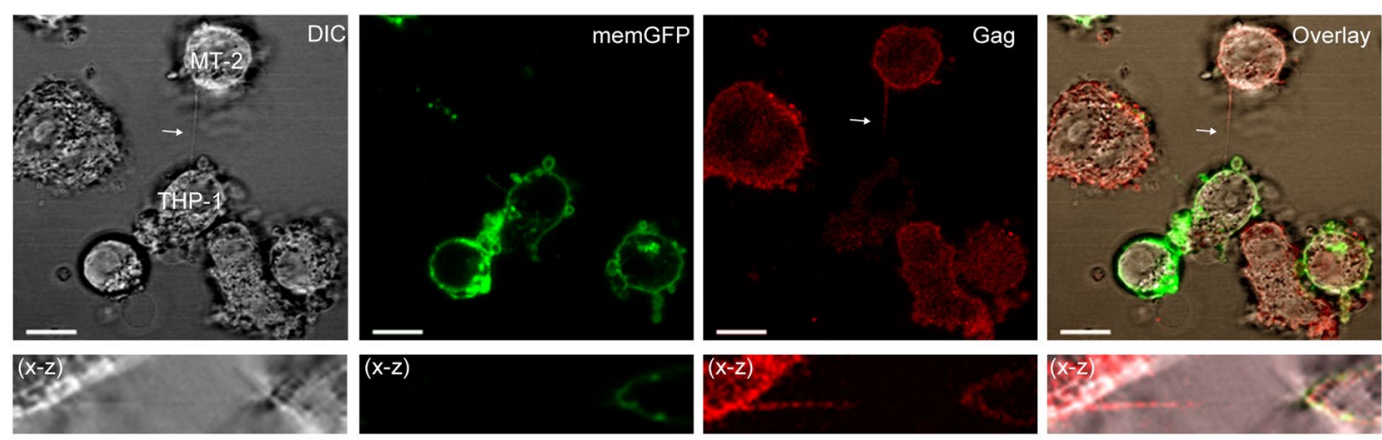

$(\mathrm{x}-\mathrm{z})$
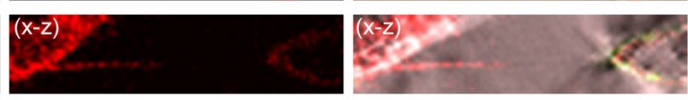

B
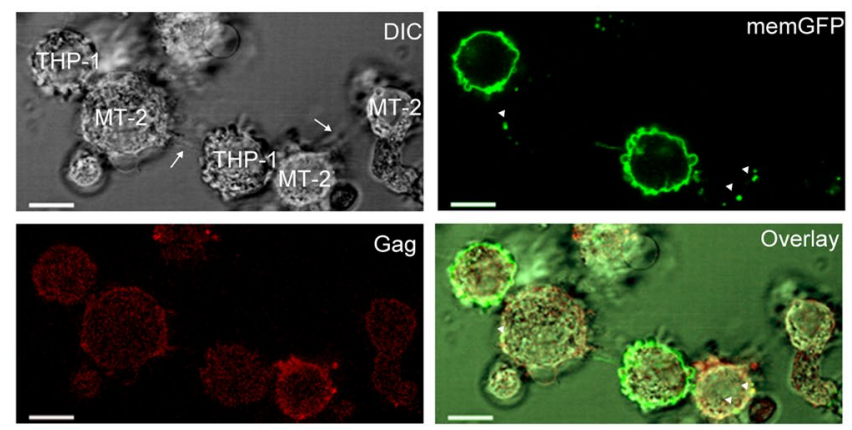

C
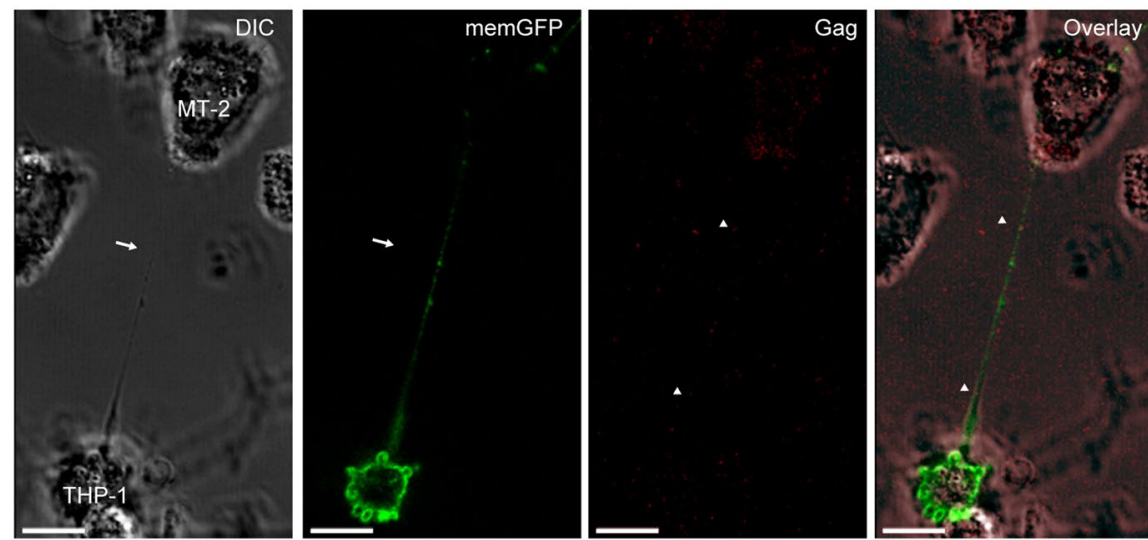

Figure 4. Gag present in TNT connecting HTLV-1 expressing cells and non-infected monocytes. (A-C) MT-2 cells and THP1-memGFP (green) cells were co-cultured overnight, fixed and stained for p24Gag (red) before investigated for TNT connections by DIC and fluorescent confocal microscopy. Arrows indicate TNTs and arrowheads Gag. The X-Z plane is obtained from a Z-stack (total 23 slices of $1 \mu \mathrm{m}$ each). Images are representatives of three independent experiments performed in duplicates. Scale bar $10 \mu \mathrm{m}$.

the MT- 2 cells towards the THP- 1 cells (Fig. 4A). When TNTs formed between MT- 2 and THP-1 were quantified for the presence of Gag or Tax, we found an average of $40 \%$ of TNTs containing Gag and 18\% containing Tax (Supplementary Fig. 1D). Both tight, direct cell-to-cell contacts and TNTs were observed between MT-2 and THP-1 cells where some cells also simultaneously engaged in TNT communication and direct contacts (Fig. 4A). We further observed that when a THP-1 cell and a MT-2 cell formed a tight connection both the THP-1 cell and the MT-2 cell formed TNT connections with two MT-2 cells on separate sites of the direct contact site (Fig. 4B). Finally, both Gag and memGFP proteins were also localized to the TNTs originating from THP-1 cells and connecting to MT-2 cells (Fig. 4C). This memGFP or Gag was demonstrated to be intracellular by a 3D reconstruction of a Z-stack from Fig. 4A (Supplementary Video 2).

Cytarabine treatment reduces TNT numbers in HTLV-1 expressing cells. Cytarabine (AraC) is a deoxycytidine analogue (Fig. 5A) which combined with an anthracycline represents standard induction therapy for treatment of AML patients ${ }^{55}$. We have previously demonstrated that clinical relevant doses of cytara-

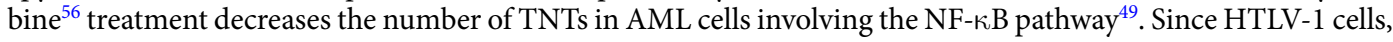




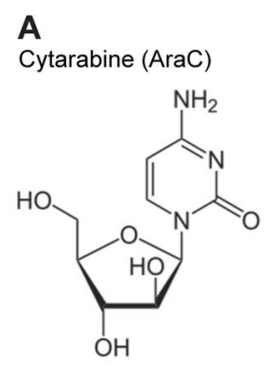

D

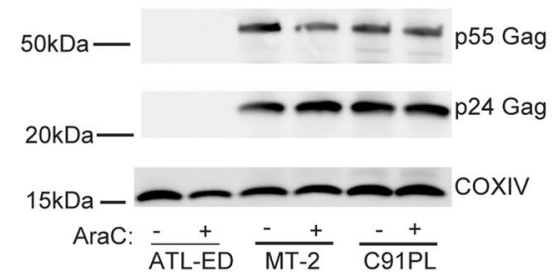

$\mathbf{F}$

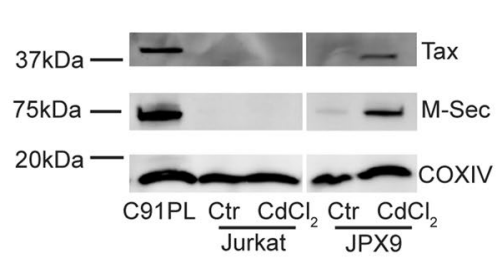

B

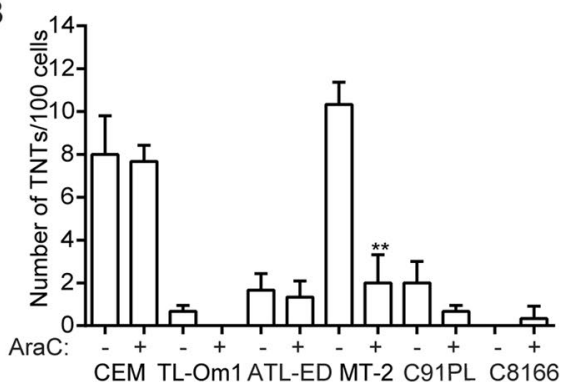

C

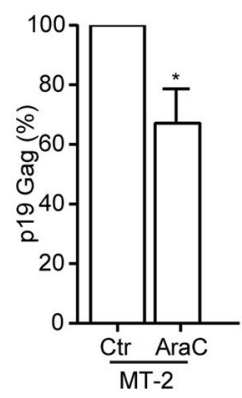

E

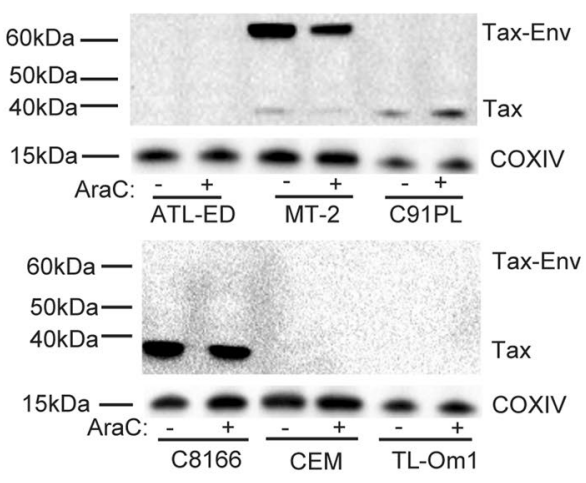

G

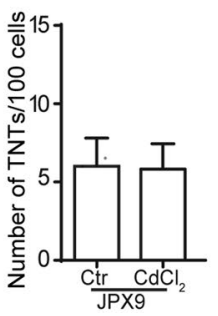

Figure 5. Cytarabine treatment reduces TNT numbers in HTLV-1 expressing cells. (A) Molecular structure of cytarabine (AraC). (B) Quantification of TNTs in cell lines before and after cytarabine (AraC) treatment $(1 \mu \mathrm{M}, 24 \mathrm{~h})$. (C) Quantification of $\mathrm{p} 19 \mathrm{Gag}(\mathrm{pg} / \mathrm{ml})$ by the HTLV-1 antigen capturing ELISA kit in MT-2 supernatant before and after treatment with $\operatorname{AraC}(1 \mu \mathrm{M}, 24 \mathrm{~h})$. (D) Immunoblotting of ATL-ED, MT-2 and C91PL cells before and after treatment with $\operatorname{AraC}(1 \mu \mathrm{M}, 24 \mathrm{~h})$ with antibodies against p24/p55 Gag and COXIV (loading control). (E) Immunoblotting of C8166, CEM, TL-Om1, ATL-ED, MT-2 and C91PL cells before and after treatment with $\mathrm{AraC}(1 \mu \mathrm{M}, 24 \mathrm{~h})$ with antibodies against Tax and COXIV (loading control). (F) Immunoblotting of Jurkat and JPX9 (Tax wt) cells, before and after $\mathrm{CdCl}_{2}$ treatment; antibodies against Tax, M-Sec and COXIV (loading control). Lysates of C91PL cells: positive control of Tax and M-Sec expression. Results are representative of three independent experiments. (G) Quantification of TNTs in JPX9 cells before and after treatment with $\mathrm{CdCl}_{2}$. All error bars indicate the mean \pm standard deviation. For TNT quantifications; all data are presented as three independent experiments in duplicates, p19 Gag quantifications; all data are presented in percentage as three independent experiments. The immunoblots are representatives of three independent experiments. Unpaired t-test was performed to evaluate statistic significance. F-test was performed for individual variation. GraphPad Prism (Version 6.03) was used $(* p<0.05, * * p<0.01)$. Scale bars: $10 \mu \mathrm{m}$. Full-length immunoblots are presented in Supplementary Fig. 2.

similar to AML cells are known to express a constitutive active NF-kB pathway mediated by Tax $^{57,58}$, we studied the effect of cytarabine on TNTs in HTLV-1 infected cells and the HTLV-1 negative T-cell line CEM. MT-2, C91PL, TL-Om1, ATL-ED and CEM cells were treated with $1 \mu \mathrm{M}$ cytarabine for $24 \mathrm{~h}$ followed by fixation of the HTLV-1 expressing cell lines, and TNT quantification compared to non-treated cells (Fig. 5B). This caused 11\% cell death in the MT-2 cells and $<5 \%$ in the other cell lines as determined by Hoechst 33342 staining following microscopy (data not shown) and TNT numbers were quantified between live cells only and these were significantly reduced in the MT-2 cells after cytarabine treatment, whereas no significant change was found in CEM cells (Fig. 5B). The other HTLV-1 positive cell lines that expressed low TNT numbers demonstrated minor reductions after cytarabine treatment. To determine if cytarabine treatment affected viral release, $\mathrm{p} 19 \mathrm{Gag}(\mathrm{pg} / \mathrm{ml})$ was measured in the supernatant of mock treated or $1 \mu \mathrm{M}$ cytarabine treated MT- 2 cells. Cytarabine treatment resulted in approximately $30 \%$ reduction in p19Gag (Fig. 5C). When intracellular p24Gag in MT-2 cells was evaluated by immunoblotting after $24 \mathrm{~h}$ of cytarabine $(1 \mu \mathrm{M})$ treatment, we found a reduction in the p55Gag precursor and 
an increase in p24Gag (Fig. 5D). Whereas this was not as evident in the cytarabine treated C91PL cells (Fig. 5D). Further, cytarabine treatment also resulted in reduced Tax protein expression in MT-2 cells (Fig. 5E) indicating an association between Tax and TNT numbers.

To further investigate the role of Tax in TNT formation, we used the Jurkat derived cell line JPX9 which can be induced with $\mathrm{CdCl}_{2}$ to express $\mathrm{Tax}^{59}$. Although we could detect induction of Tax protein in the JPX9 cells by immunoblotting (Fig. 5F), we found no difference in TNT numbers (Fig. 5G). The induction of wildtype Tax also increased expression of the M-Sec (TNF alpha inducing protein 2) protein (Fig. 5G), previously reported to be a central protein for TNT formation ${ }^{60}$. Based on this we concluded that Tax and M-Sec most likely are not essential for TNT formation in HTLV-1 infected cells.

Cytarabine reduces viral transmission. To determine if cytarabine affected cell-to-cell transfer and infection, we utilized the BHK1E6 cell reporter system. The BHK1E6 cells contains the lacZ gene driven by the HTLV-LTR promoter, allowing $\beta$-galactosidase to be used as a measure of LTR activation by Tax ${ }^{61}$. First, the BHK1E6 cells were investigated for the presence of TNTs before and after treatment with cytarabine $(1 \mu \mathrm{M})$ for $24 \mathrm{~h}$. The BHK1E6 cells expressed on average $2 \mathrm{TNTs} / 100$ cells which did not change after cytarabine treatment and no cell death was found in the BHK1E6 cells after treatment as compared to MT-2 cells (Fig. 6A). TNT-like structures were observed interconnecting MT-2 and BHK1E6 cells after co-culture (data not shown) and the percent of $\beta$-galactosidase production was significantly reduced by approximately $25 \%$ in the presence of cytarabine $(1 \mu \mathrm{M}, 24 \mathrm{~h})$ and a consistent, but not significant, reduction of cell supernatant p19Gag was found (Fig. 6B,C). To investigate viral transfer by the use of newly HTLV-1 infected cells, we infected primary sorted CD $4^{+}$cells from healthy peripheral blood mononuclear cells by co-culturing with lethally $\gamma$-irradiated 729.6 cells expressing the HTLV-1 molecular clone pAB, as previously described ${ }^{37}$. This molecular clone contains an orf-I encoding for an aspartic acid in position 26 resulting in equal expression of p12 and p8 proteins ${ }^{36}$ and therefore these newly infected $\mathrm{CD} 4^{+}$cells are named CD4 ${ }^{+}$-pAB-D26. Cell purity of the CD4 ${ }^{+}$-pAB-D26 cells was measured by flow cytometry while verification of the presence of HTLV-1 Gag was performed by PCR on isolated DNA and the proviral load was found to be $265.6 \%$ at day 58 in culture (Fig. 6D and Supplementary Fig. 3). The calculation of proviral load (\%) was based on the copy number of $H T L V-1$ per 100 of copy number of the RNase P gene. When the CD4 ${ }^{+}$-pAB-D26 cells were co-cultured with the BHK1E6 cells TNT-like structures were observed between these cells (Fig. $6 \mathrm{E})$. Following treatment for $24 \mathrm{~h}$ with cytarabine $(1 \mu \mathrm{M}, 5 \%$ cell death measured by Hoechst 33342 staining) or the reverse transcriptase inhibitor AZT (azidothymidine, zidovudine, $10 \mu \mathrm{M}, 4 \%$ cell death measured by Hoechst 33342 staining), included as one of the treatment options of ATL patients today ${ }^{62}$, we found that the number of TNT-like structures connecting the CD4 ${ }^{+}$-pAB-D26 cells and BHK1E6 cells were reduced by $44 \%$ after treatment with cytarabine, but not AZT (Fig. 6F) and interestingly, cytarabine treatment resulted in a $30 \%$ decrease in number of $\beta$-galactosidase positive cells (Fig. 6G). No significant change of p19Gag in the supernatant of the co-culture was found (Fig. $6 \mathrm{H}$ ), therefore not explaining the reduction of blue cells ( $\beta$-gal positive) in the transmission assay. We have previously shown that cytarabine can inhibit TNT formation ${ }^{49}$, but here we do not exclude other transmission mechanisms of Tax transfer to the BHK1E6 cells. Since Tax have been found in exosomes $^{63}$ the difference in reduction between TNT-like structures and $\beta$-galactosidase positive cells could be explained by an exchange of vesicles or other means of Tax transfer. In conclusion we find that $24 \mathrm{~h}$ treatment of cytarabine reduce viral transmission, not found after AZT treatment.

p8 induces TNT formation in uninfected T-cells. Because we earlier reported that p8 induced cellular conduits and we observed a difference in TNT forming capabilities among the HTLV-1 positive cell lines, we investigated the orf-I sequence in these cells (Fig. 7A). Interestingly, the MT-2 cell line which had the highest TNT numbers, contained a provirus encoding an asparagine at position 26 (N26) of orf-I, an isoform we previously demonstrated to mainly express the $\mathrm{p} 8$ protein an inducer of viral transmission ${ }^{34,36}$. Except for the C91PL cells, the remaining HTLV-1 cell lines, including the primary infected CD4 ${ }^{+}$pAB-D26 cells, encoded the isoform with an aspartic acid at position 26 (D26) resulting in approximately equivalent expression of $\mathrm{p} 12$ and $\mathrm{p} 8^{36}$. The C91PL cell line contained provirus encoding a glycine in position 26 (G26) also found to express equal amounts of p12 and $\mathrm{p} 8$ proteins (unpublished data).

To further investigate the role of p8 in TNT formation, we stably transduced Jurkat memCherry cells with either a GFP-expressing lentiviral empty vector control (pSDM) or pSDM expressing an orf-I unable to be pro-

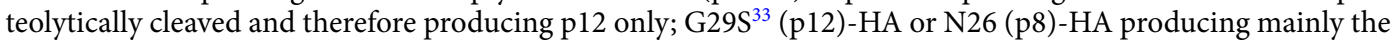
p8 protein ${ }^{36}$. The transduction efficiency was determined by flow cytometry as percentage GFP-positive cells; pSDM: 96\%, pSDM-N26(p8)-HA: 69\% and pSDM-G29S(p12)-HA: 87\% (Fig. 7B) and expression was verified by immunoblotting (Fig. 7C). Following this, live cell TNT quantification was performed including GFP-positive cells only. We found that compared to the Jurkat-memCherry cells only, the transduction by pSDM resulted in reduced TNT numbers, however, no significant differences were found between the pSDM cells and the pSDM-G29S(p12)-HA cells (Fig. 7D). The pSDM-N26(p8)-HA positive cells showed a significant induction of TNTs $(p=0.0088)$ compared to the pSDM or pSDM-G29S(p12)-HA positive cells (Fig. 7D). The structures were verified as containing F-actin and devoid of tubulin. However, tubulin could be detected at both ends of the TNT structure (Fig. 7E), as also observed by others ${ }^{64}$. Consistent with what we observed in HTLV-1 producing cells, treatment of pSDM-N26(p8)-HA expressing cells with $1 \mu \mathrm{M}$ cytarabine (8\% cell death measured by Hoechst 33342 staining) resulted in a significant $(\mathrm{p}<0.0001)$ down-regulation of the TNT formation (Fig. 7F) without affecting p8 expression (Fig. 7G).

Taken together, we have shown that HTLV-1 expressing cells are interconnected by the strictly defined intercellular structures TNTs as well as with uninfected T-cells and monocytes. TNTs were found to originate from either HTLV-1 positive cells or HTLV-1 negative cells. Using memGFP and memCherry stably expressing cells we found the presence of both memGFP, memCherry, Tax and Gag proteins in the TNTs indicating potential 
A

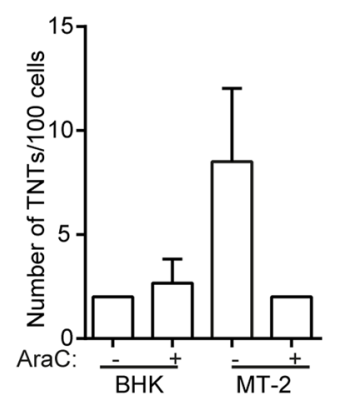

D

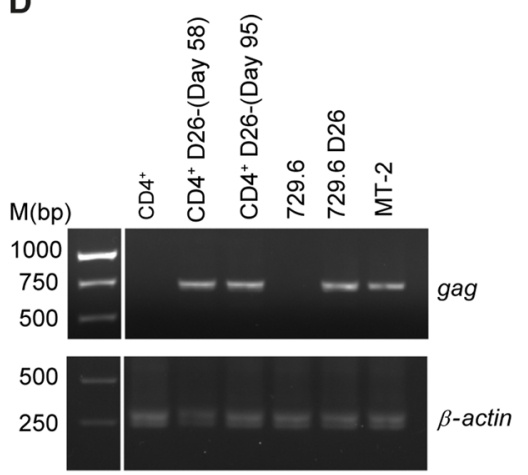

B

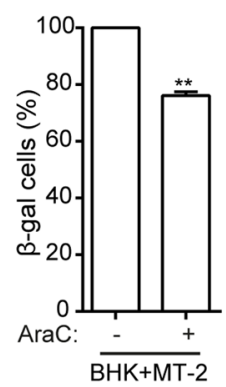

C

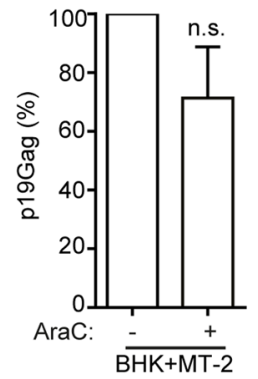

E
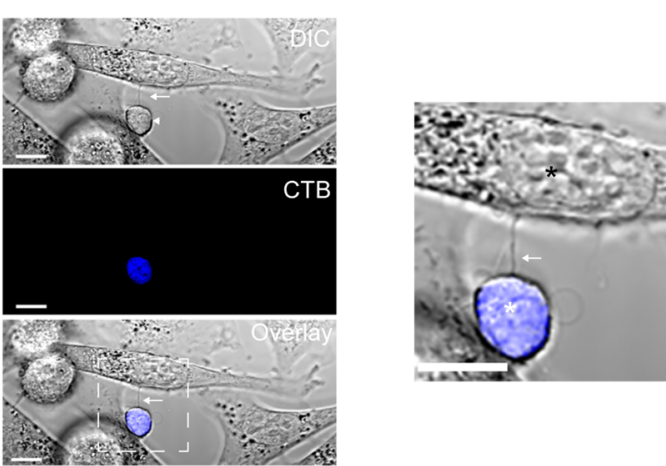

$\mathbf{F}$

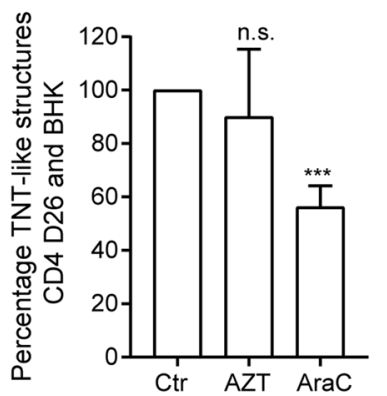

G

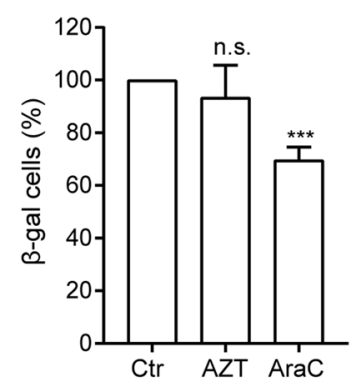

H

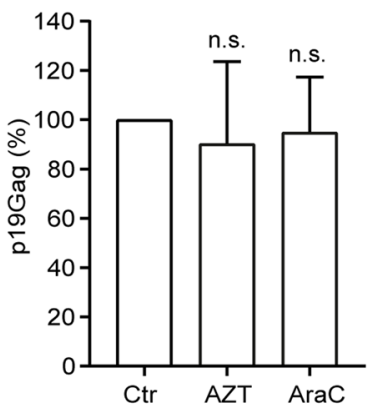

Figure 6. Cytarabine, but not AZT significantly inhibits viral transmission and TNT-like structures between primary CD4 ${ }^{+}$-pAB-D26 and BHK1E6 cells (A) TNT quantification of BHK1E6 cells (BHK) and MT-2 cells before and after cytarabine $(\mathrm{AraC})$ treatment $(1 \mu \mathrm{M}, 24 \mathrm{~h})$. TNTs quantified between mono-cultures of BHK1E6 and MT-2 cells. (B) Co-culture of MT-2 and BHK1E6 (BHK) cells (24h) with $1 \mu \mathrm{M} \mathrm{AraC}$ or ctr stained for $\beta$-galactosidase activity (blue cells), percentage of three independent experiments performed in duplicates. (C) Quantification of $19 \mathrm{Gag}(\mathrm{pg} / \mathrm{ml})$ in supernatants of co-culture experiments in (B) by the HTLV-1 antigen capturing ELISA kit (D) Validation of Gag presence in primary CD4 $4^{+}$-pAB-D26 cells by PCR, uninfected $\mathrm{CD}^{+}$cells and 729.6 cells are shown as negative controls, 729.6-pAB-D26 and MT-2 cells are shown as positive controls. (E) TNT-like structure between cell tracker blue stained CD4+ $4^{+}$-pAB-D26 in co-culture with BHK1E6 cells, arrow indicate TNT-like structure. In zoomed image black star indicate BHK1E6 cell and white star $\mathrm{CD} 4^{+}$-pAB-D26. Image is representative of three independent experiments performed in duplicates. (F) Quantification of TNT-like structures between $\mathrm{CD} 4^{+}-\mathrm{pAB}-\mathrm{D} 26$ and BHK1E6 cells co-cultured for $24 \mathrm{~h}$ with $10 \mu \mathrm{M} \mathrm{AZT}, 1 \mu \mathrm{M}$ AraC or medium only. $100 \mathrm{CD}^{+}{ }^{+}$D26 cells were counted in each experiment. Mean percentage from three independent experiments performed in duplicates are shown. (G) Co-culture of CD4 ${ }^{+}$pAB-D26 cells and BHK1E6 cells ( $24 \mathrm{~h}$ ) with ctr, $10 \mu \mathrm{M}$ AZT or $1 \mu \mathrm{M}$ AraC stained for $\beta$-galactosidase activity (blue cells), percentage of three independent experiments performed in duplicates. (H) Quantification of p19 $\mathrm{Gag}(\mathrm{pg} / \mathrm{ml})$ in supernatants of co-culture experiments in (G) by the HTLV-1 antigen capturing ELISA kit. All p19 Gag quantifications are presented in percentage of three independent experiments. All error bars indicate the mean \pm standard deviation. Unpaired t-test was performed to evaluate statistical significance. F-test was performed for individual variation. GraphPad Prism (Version 6.03) was used (** $p \leq 0.01,{ }^{* * *} p \leq 0.001$, n.s. not significant). Full-length gel images are presented in Supplementary Fig. 4. 
A

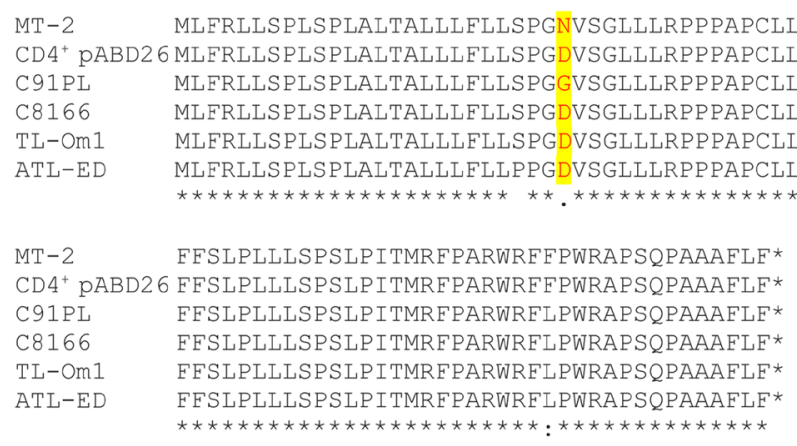
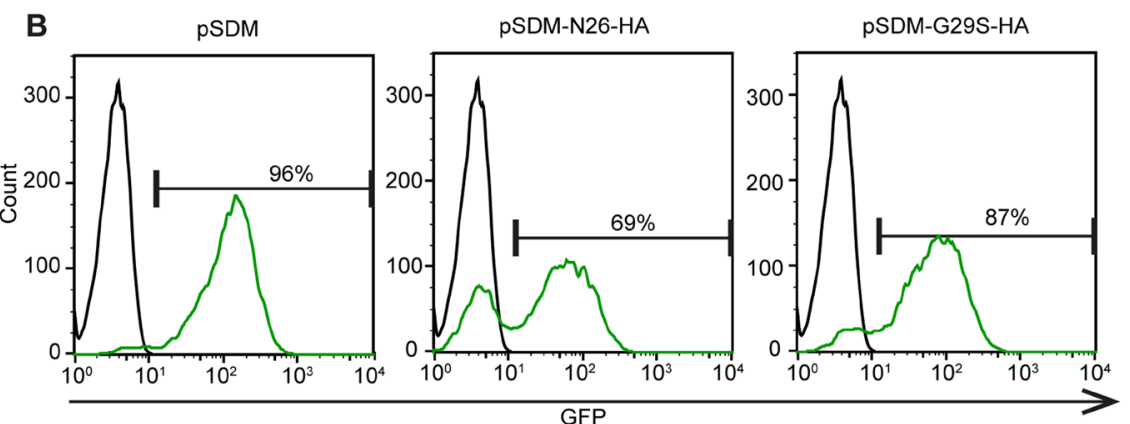

C

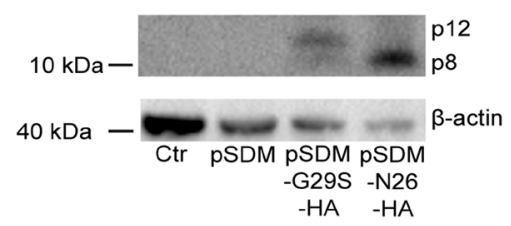

E

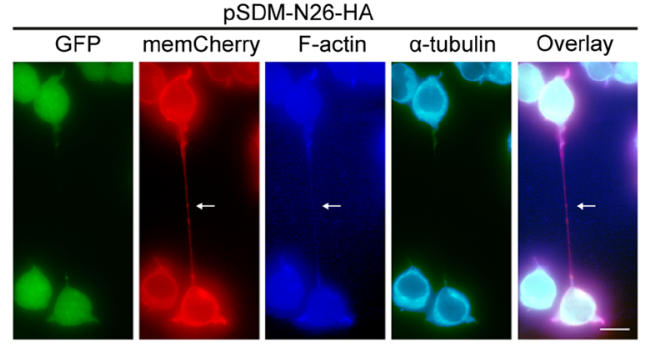

D

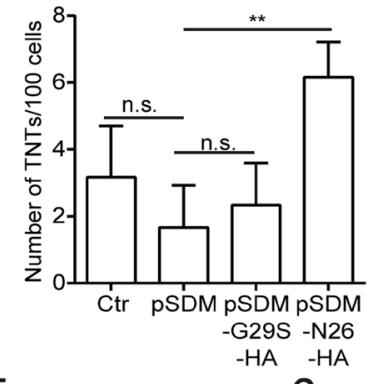

$\mathbf{F}$

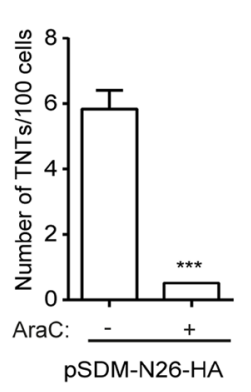

G

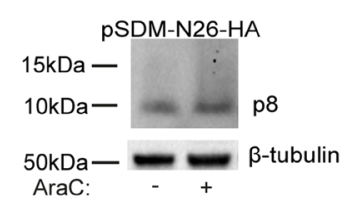

Figure 7. The p8 protein increases TNT formation. (A) Orf-I amino acid sequences of HTLV-1 positive cell lines. (B) Transduction efficiency determined by flow cytometry of percentage GFP positive cells in Jurkat-memCherry cells transduced with pSDM, pSDM-N26(p8)-HA or pSDM-G29S(p12)-HA. (C) Immunoblotting of JurkatmemCherry cells (ctr), Jurkat-memCherry; pSDM, pSDM-G29S-HA and pSDM-N26-HA incubated with anti-HA antibody. $\beta$-actin was used as loading control. (D) TNT quantification of Jurkat-memCherry; pSDM, pSDMG29S-HA and pSDM-N26-HA. Results are presented as mean from three independent experiments performed in duplicates. (E) TNT verification in Jurkat-memCherry-pSDM-N26-HA cells. The cells were fixed and stained with AF350 phalloidin to visualize F-actin (blue) and anti- $\alpha$-tubulin to visualize tubulin (cyan, AF633), transduced cells are GFP positive, plasma membrane memCherry (red). Scale bar: $10 \mu \mathrm{m}$. Result is representative of three independent experiments. (F) Jurkat-memCherry-pSDM-N26-HA cells were untreated or treated with $1 \mu \mathrm{M}$ cytarabine $(\mathrm{AraC})$ for $24 \mathrm{~h}$ and TNTs were quantified in live cells. Results are shown as mean from three independent experiments performed in duplicates. (G) Immunoblotting of Jurkat-memCherry-pSDM-N26-HA cells not treated or treated with $1 \mu \mathrm{M}$ AraC incubated with anti-HA antibody. $\beta$-tubulin was used as loading control. Representative blot of three independent experiments is shown. Unpaired t-test was performed to evaluate statistic significance. F-test was performed for individual variation. GraphPad Prism (Version 6.03) was used (** $p<0.01$, *** $p \leq 0.001$ ). Full-length immunoblots are presented in Supplementary Fig. 5. Adobe photoshop CS6 was used to prepare the images. The contrast was enhanced on the whole image to better represent and visualize the thin TNT structures. 
transport of these proteins through the TNTs. Cytarabine treatment resulted in a reduction of TNTs, virus production and viral transmission. Expression of orf-I-N26 in Jurkat cells enhanced number of TNT formation significantly reduced by cytarabine treatment.

\section{Discussion}

TNTs represent direct long distance cell-to-cell communication where cells can exchange material. TNTs have been suggested to play a role in different diseases such as cancer and infectious diseases involving chemoresistance and spread of pathogens $s^{47-49,65-70}$.

Retroviruses exploit host cells for their replication and viral spread. HTLV-1, in particular, is highly dependent on cell-to-cell interaction between immune cells for successful transfer and establishment of productive infection $^{28}$. Here we find that the HTLV-1 infected cells fulfilled the strict definition for being a TNT. These cells expressed thin intercellular connections at least $5 \mu \mathrm{m}$ in length that lacked contact with the substratum. MT-2 cells contained F-actin and lacked tubulin and by scanning electron microscopy (SEM) these structures were verified to be thin $(<200 \mathrm{~nm})$ and interestingly often with a branched anchor point, which has been previously described for $\mathrm{TNTs}^{53}$. These TNTs were frequently observed having multiple knobs indicating transport.

Variation in the number of TNTs was seen among the HTLV-1 infected cell lines. The ATL T-cell lines (TL-Om1, ATL-ED) which have integrated provirus, but do not express Tax or release virus, formed less TNTs than the HTLV-1 producing cell line MT-2 and showed more similarity to the HTLV-1 expressing cell line C91PL and the C8166 cell line, containing a defect provirus, but expressing Tax protein. However, TNT quantification was challenging in the C91PL and C8166 cells due to their cell culture growth in large clusters particularly difficult to separate into single cells. In cell cultures, many T-cell lines grow in clusters most likely reflecting expression of cell surface adhesion molecules and this expression and distribution could impact TNT formation. In cells that grow in such close proximity viruses will most likely exploit close contact cell-to-cell communication rather than long-distance TNT communication.

Both membrane nanotubes as well as cellular conduits have previously been reported to connect infected and uninfected T-cells ${ }^{34,48}$. Sowinski and co-workers demonstrated transfer of the Human Immunodeficency Virus type 1 (HIV-1) viral proteins Gag and Env between two populations of T-cells ${ }^{48}$. We showed previously that cellular conduits could be used to transport Gag and the HTLV-1 encoded p8 protein from MT- 2 cells to uninfected Jurkat cells ${ }^{34}$. In addition to defining the cellular structures, we wanted to investigate, using co-culture systems, the cellular origin of the TNTs formed. For this purpose we generated Jurkat and THP-1 cells stably expressing memCherry or memGFP, respectively. Membrane nanotubes have previously been reported for Jurkat and THP-1 cells $^{48}$. We were particularly interested in looking at TNT formation between T-cells and monocytes since we recently demonstrated viral DNA in three different monocyte subsets from HTLV-1 infected individuals ${ }^{12}$. In addition, HTLV-1 infection of the monocytes is associated with changes in surface marker expression and function $^{12}$. First, we established that THP-1 and Jurkat cells could form TNTs with infected T-cells and these originated from both cell types. This suggested, similar to what was reported by Sowinski and co-workers for T-cells, that the TNTs formed between T-cells and monocytes are not open-ended ${ }^{48}$. The consequence of this feature is that potential transport of cargo is not passive solely through a sheared membrane but mostly involve an active and motor driven transport. Further verification of the components of the TNTs formed is needed to conclude how this transport is occurring, by staining with motor proteins such as Myosin $\mathrm{Va}^{39,48,71}$. We found that TNT formation between infected and uninfected cells originated from both; from MT- 2 cells to Jurkat and THP-1 cells or from Jurkat and THP-1 cells to MT-2 cells. Interestingly, following quantification, the Tax protein was localized to $18 \%$ of TNTs connecting MT-2 and THP-1 cells. Tax protein was also found localized to TNTs originating from THP-1 towards MT-2 cells. This could indicate transport of Tax protein from MT-2 cells towards uninfected cells using TNTs generated by the uninfected cells. Since these HTLV-1 producing cells required fixation, we were unfortunately not able to perform time-lapse live-cell imaging to further investigate Tax transport through the TNTs. Because Tax protein has not been demonstrated to be part of the viral particle, transfer of Tax protein is likely independent of viral infection of the recipient cell. Tax transfer could induce a variety of changes in an uninfected cell as Tax has been shown to affect a large number of cellular pathways ${ }^{58}$. Future studies establishing assays to investigate functional effect of Tax transfer are needed. In addition, we observed GFP positive dots in the MT-2 cells, implying an exchange of cargo in both directions. These observations support the possibility that HTLV-1 infected cells can utilize TNTs generated from an uninfected cell towards the infected to transport viral proteins, signaling molecules and the virus itself. Consistent with this, we found Gag in $40 \%$ of the TNTs connecting MT-2 cells and THP-1 cells. As seen with Tax, the Gag protein was also observed in the TNTs originating from the THP-1 cells. The Gag protein in the TNTs could represent Gag included as part of the viral particle, and/or it can also represent the Gag protein alone. Future studies are needed to better characterize virus particles actively transported through the TNTs.

We frequently observed that TNTs formed from one or both cells already in direct contact with other cells. This could point to that the previously described virological synapse and biofilm-like structures could be processes occurring simultaneously with TNT formation and one process could also activate the start of another. Meaning that when TNTs are used for transfer of virus and viral proteins it could be part of several approaches each cell can exploit for viral spread.

We have previously shown that TNT formation was downregulated by cytarabine treatment through a NF-кB dependent mechanism in AML cells ${ }^{49}$. Since HTLV-1 infected cells share some features with AML cells, such as constitutive activation of the NF-кB-pathway, MT-2 cells were treated with a clinically relevant ${ }^{56}$ and pre-apoptotic dose of cytarabine $(1 \mu \mathrm{M})$ for $24 \mathrm{~h}(\leq 11 \%$ death). This treatment resulted in reduced TNT numbers and reduced levels of Tax protein. Interestingly, in MT-2 cells we found that, the p24 Gag protein was slightly increased after cytarabine treatment with a corresponding decrease in the precursor p55 Gag. We also noted a $33 \%$ reduction in the amount of supernatant p19 Gag. This suggest that cytarabine could alter Gag processing 
and the budding process of the virus. Since Tax is known to cause constitutive activation of NF- $\kappa$ B and cytarabine decreased Tax protein levels, we investigated the potential role of Tax in TNT formation using a Tax inducible Jurkat-derived cell line $e^{58,72}$. Induction of Tax showed an increase of the tumor necrosis factor $\alpha$ inducible protein 2 (TNFoIP2) also called M-Sec. M-Sec is suggested to be a key player in TNT formation ${ }^{44,60}$. However, no significant differences in TNT numbers was found between the Tax-induced cells and non-induced cells, consistent with our previous results ${ }^{34}$. This indicates that in these T-cells TNT formation is not significantly regulated by $\mathrm{M}-\mathrm{Sec}$ and/or Tax expression and that TNT formation most likely is regulated different in AML cells compared to HTLV-1 infected cells.

We demonstrate in this study that the viral protein $\mathrm{p} 8$ induced TNT formation and that the variation found among the HTLV-1 positive cell lines corresponded with the orf-I isoform expressed. The cell lines which had low TNT formation (TL-Om1, ATL-ED, C91PL and C8166) all encoded an orf-I isoform previously demonstrated to express both $\mathrm{p} 12$ and $\mathrm{p} 8$ proteins; whereas MT-2 cells encoded for an orf- $I$ isoform mostly expressing the p8 isoform. Likewise, in T-cells transduced with lentivirus that expressed orf-I-N26, thus p8, we saw an increase in TNT formation which was down-regulated by cytarabine treatment.

To investigate if HTLV-1 transfer was affected by cytarabine, we performed a viral transmission assay by co-culturing BHK1E6 containing a lacZ reporter gene driven by the HTLV-1 LTR promoter with MT-2 cells. MT- 2 cells generated TNT-like structures with the BHK1E6 cells and cytarabine treatment reduced the number of $\beta$-galactosidase positive BHK1E6 cells by $25 \%$ indicating that cytarabine can inhibit viral transfer.

The anti-viral effects of cytarabine and down-regulation of Tax make cytarabine an interesting drug for further studies. The Tax protein has been shown to have pleiotropic effects and is proposed to be involved in the transformation of T-cells in ATL ${ }^{58,73}$. Despite little or no viral expression about $40 \%$ of ATL patients continue to express Tax in their HTLV-1 infected T-cells ${ }^{74}$. Drugs that affect Tax expression and NF- $\kappa$ B activation have been used as therapeutics in $\mathrm{ATL}^{58}$. Others have shown that the combination of arsenic trioxide and interferon alpha is an effective ATL treatment due to degradation of $\operatorname{Tax}^{75,76}$. Cytarabine could therefore potentially represent an alternative for use in ATL treatment, further supported by the fact that the down-regulation of viral expression was caused by the use of a clinical relevant dose of cytarabine ${ }^{56}$. Since higher viral loads are associated with disease progression 77,78 cytarabine, because of its effects on TNT formation and HTLV-1 transmission could represent a promising therapeutic. It would be of interest to further investigate the efficacy of cytarabine in in vivo animal models of HTLV-1.

\section{Material and Methods}

Cells and culture conditions. The HTLV-1 positive cell lines MT-2, C91PL, C8166, TL-Om1 and ATL-ED and the HTLV-1 negative cell lines Jurkat, THP-1 and the Tax inducible cells JPX9 cells (kind gift from the laboratory of Dr. Giam at USHS) were all grown in RPMI-1640 medium. The BHK1E6 (HTLV-1-LTR-lacZ) cells ${ }^{61}$ were grown in Dulbecco's modified eagles medium (DMEM). All cell culture media were supplemented with $10 \%$ fetal bovine serum (FBS), $2 \mathrm{mg} / \mathrm{mL}$ L-glutamine, $100 \mathrm{U}$ Penicillin and $100 \mu \mathrm{g} / \mathrm{mL}$ Streptomycin (Quality Biological). Human peripheral blood T-cells (or buffy coats/leukapheresis packs) were obtained from healthy donors on NCI IRB-approved NIH protocol 99-CC-0168. Research blood donors provided written informed consent and blood samples were de-identified prior to distribution, in accordance with the Declaration of Helsinki.

The primary CD4 ${ }^{+}$-pAB-D26 cells were cultured in RPMI-1640 medium supplemented with $20 \%$ FBS and $100 \mathrm{U}$ of interleukin-2 in addition to L-glutamine and antibiotics. The THP1-memGFP and Jurkat-memCherry cells were generated by transducing THP-1 and Jurkat cells with ready-to-use lentiviral particles expressing twenty amino acids of the N-terminal part of Neuromodulin containing a palmitoylation signal fused to GFP or Cherry (Takara, rLV-EF1-AcGFP-Mem-9; rV2.1A1.1941 C2, rLV.EF1.mCherry-Mem-9;rV2.1A1.2406 C2), respectively, according to manufacturer's instructions. The THP1-memGFP and Jurkat-memCherry cells were sorted by BD FACS Aria SORP at the Flow Cytometry Core Facility, Department of Clinical Science, University of Bergen, Norway.

TNT definition and quantification. 70000 cells were seeded on fibronectin $(10 \mu \mathrm{g} / \mathrm{ml})$ coated $\mu$-wells (IBIDI) and incubated for $24 \mathrm{~h}$ without or with $1 \mu \mathrm{M}$ cytarabine (AraC) (Hospira, $100 \mathrm{mg} / \mathrm{ml}$ ). Cells were stained with $1.67 \mu \mathrm{g} / \mathrm{ml}$ wheat germ agglutinin (WGA) conjugated to Alexa Fluor 488 or 594 (Life Technologies) for $8 \mathrm{~min}$ at $37^{\circ} \mathrm{C}$ and washed once with DPBS1x (Gibco) before fixation with 4\% PFA (Electron Microscopy Sciences) and $0.2 \%$ glutaraldehyde (Electron Microscopy Sciences) for $15 \mathrm{~min}$ at room temperature (RT) and gently washed twice before examined by microscopy. The TNT in the present study is defined and identified as a thin structure $(<200 \mathrm{~nm})$ interconnecting two cells, without contact with the substrate. Further, these TNTs are verified by content of F-actin and lack of microtubules. 100 cells were counted as explained previously ${ }^{49}$ in each well in duplicates and each experiment was performed as independent triplicates, unless otherwise noted. Cell viability was monitored by Hoechst 33342 (Sigma) staining as described earlier ${ }^{79}$.

TNT verification. Cells were stained with WGA-488 $(1.67 \mu \mathrm{g} / \mathrm{ml})$ for $10 \mathrm{~min}$ at RT, washed once with PBS, permeabilized with $0.2 \%$ TWEEN 20 (polyoxyethylene sorbitan monolaurate) (Bio-Rad) in PBS for 1-2 min, washed with PBS and incubated in $0.5 \%$ BSA in PBS for $1 \mathrm{~h}$ at RT. Following this, the cells were stained for F-actin by incubation with Alexa Fluor 350 phalloidin $(0.33 \mu \mathrm{M})$ for $1 \mathrm{~h}$ at RT, washed once in PBS and stained for tubulin by incubation with an $\alpha$-tubulin antibody $\left(1: 100\right.$, Sigma) overnight at $4{ }^{\circ} \mathrm{C}$. The cells were washed twice with PBS and incubated for $1 \mathrm{~h}$ at RT in the dark with goat anti-mouse Alexa Fluor 568 (1:5000, Invitrogen) or Alexa Fluor 633 (1:5000, Invitrogen). Finally, the cells were washed twice with PBS before analyzed by fluorescence microscopy. 
Immunofluorescence. Cells were fixed with 4\% PFA (Electron Microscopy Sciences,) and 0.2\% glutaraldehyde for $15 \mathrm{~min}$, washed once with PBS before permeabilized with $0.2 \%$ TWEEN 20 in PBS for $1 \mathrm{~min}$. Then the cells were washed once before blocked with $0.5 \%$ BSA in PBS for at $15 \mathrm{~min}$ at RT. The cells were then incubated for $1 \mathrm{~h}$ at RT with anti-p24 Gag antibody (ABL\#4310 ABL inc., 1:50) or overnight at $4{ }^{\circ} \mathrm{C}$ with anti-Tax monoclonal antibody (Tab172 $\left.{ }^{80}, 1: 10\right)$, before washed twice with PBS followed by incubation with goat anti-mouse Alexa Fluor 568 as described earlier. Finally, the cells were washed twice with PBS before examined by fluorescence microscopy.

Scanning electron microscopy (SEM). Coverslips added to the wells of a 24 -well plate were pre-coated with fibronectin $(10 \mu \mathrm{g} / \mathrm{ml})$ before seeding of $450000 \mathrm{MT}-2$ cells per well. The cells were incubated for $24 \mathrm{~h}$ at $37^{\circ} \mathrm{C}$ before fixed overnight at $4^{\circ} \mathrm{C}$ using $2 \%$ glutaraldehyde in $0.1 \mathrm{M} \mathrm{Na}$-cacodylate buffer. Cells were then washed $3 \times 15 \mathrm{~min}$ with $0.1 \mathrm{M} \mathrm{Na}$-cacodylate buffer, post-fixed in $1 \%$ osmiumtetraoksyd $\left(\mathrm{OsO}_{4}\right)$ in Na-cacodylate buffer for $1 \mathrm{~h}$ at $4{ }^{\circ} \mathrm{C}$, and washed $2 \times 10 \mathrm{~min}$ in $0.1 \mathrm{M} \mathrm{Na}$-cacodylate buffer before dehydration. Dehydration was performed as follows: $30 \%$ ethanol for $15 \mathrm{~min}, 50 \%$ ethanol for $15 \mathrm{~min}, 70 \%$ ethanol overnight, $96 \%$ ethanol for $20 \mathrm{~min}$ and $2 \times 100 \%$ ethanol for $20 \mathrm{~min}$. Following fixation and dehydration the coverslips were placed on SEM stubs before incubated in a heat-incubator overnight. Critical point drying was performed before the SEM stubs were coated with 5-10 $\mathrm{nm}$ gold/palladium before cells were investigated by scanning electron microscopy.

JPX9 cells. JPX9 cells are stable transfected Jurkat cells containing wildtype Tax, inducible by a metallothionein promoter ${ }^{59}$. This promoter is activated by treatment with $\mathrm{CdCl}_{2}$. JPX9 cells $\left(1.5-2.5 \times 10^{6}\right)$ were seeded in 6-well plates without or with $20 \mu \mathrm{M} \mathrm{CdCl}_{2}$ (Sigma) for $48 \mathrm{~h}$ and Tax expression was verified by immunoblot analysis. For microscopy analysis, 35000 cells were seeded onto fibronectin pre-coated $\mu$-wells, non-treated or treated with $20 \mu \mathrm{M} \mathrm{CdCl}_{2}$ for $48 \mathrm{~h}$ before stained with WGA- 488 and examined by live cell microscopy.

Co-culture assays. $1 \times 10^{6}$ BHK1E6 cells were seeded per well in 6-well plates and incubated overnight. The MT-2 cells were washed once with saline before co-culturing of $1 \times 10^{6}$ cells with pre-seeded BHK1E6 cells. For primary CD4 ${ }^{+}$-pAB-D26 cells the cells were centrifuged 5 min 1500 RPM and added RPMI-1640 medium supplemented with $20 \%$ FBS and $100 \mathrm{U}$ of interleukin-2 in a $1 \times 10^{6}$ cells/ml dilution and added to BHK1E6 cells. Co-cultured cells were untreated or treated with $1 \mu \mathrm{M}$ cytarabine for $24 \mathrm{~h}$. Supernatants were collected for analysis by the p19 Gag antigen capturing assay and the cells were washed twice with PBS, fixed in $4 \%$ PFA for 20 min and stained with the $\beta$-galactosidase kit (cat\#: 35001, Active motif), according to manufactures protocol and incubated overnight at $37^{\circ} \mathrm{C}$. Following this the cells were washed twice with PBS blue cells were scored using light microscopy. TNT quantification of BHK1E6 cells in co-culture with MT-2 cells; 5000 BHK1E6 cells were seeded on fibronectin pre-coated $\mu$-wells and incubated overnight before addition of $20000 \mathrm{MT}-2$ cells without or with $1 \mu \mathrm{M}$ cytarabine or $10 \mu \mathrm{M}$ AZT (azidothymidine, zidovudine) treatment for $24 \mathrm{~h}$. All experiments performed in duplicates and independently repeated three times. TNT quantification of BHK1E6 or MT-2 cells; 10000 BHK1E6 cells or 70000 MT-2 cells were seeded in separate wells without or with treatment with $1 \mu \mathrm{M}$ cytarabine. Cells were fixed with $4 \%$ PFA for 20 min before examined by microscopy.

For co-culture of BHK1E6 and primary $\mathrm{CD}^{+}-\mathrm{pAB}-\mathrm{D} 26$ cells, 5000 BHK1E6 cells were seeded on fibronectin pre-coated $\mu$-wells (IBIDI) one day before addition of CD4 ${ }^{+}$pAB-D26 cells. CD4 ${ }^{+}$-pAB-D26 cells were stained with celltracker blue CMAC (7-amino-4-chloromethylcoumarin, $25 \mu \mathrm{M}$ ) as described earlier ${ }^{49} .20000$ celltracker blue stained $\mathrm{CD} 4^{+}$pAB-D26 cells were added to the BHK1E6 cells and culture medium suitable for the $\mathrm{CD}^{+}$-pAB-D26 cells was used for the co-culture added $1 \mu \mathrm{M}$ cytarabine or $10 \mu \mathrm{M}$ AZT. Cells were fixed and stained as described with MT-2 cells after $24 \mathrm{~h}$ co-culture.

For co-cultures between MT-2 and THP-1-memGFP cells, 56000 MT-2 cells and 14000 THP1-memGFP cells were plated on a fibronectin pre-coated $8 \mu$-well IBIDI. All experiments were independently repeated three times.

p19 Gag antigen-capturing assay. Briefly, supernatants from cells were collected and centrifuged at 1800 $\mathrm{rpm}$ for $5 \mathrm{~min}$ at RT. The supernatants were transferred to a fresh collection tube and stored at $-80^{\circ} \mathrm{C}$ until further analysis. The p19 Gag was measured by the p19 Gag antigen-capturing ELISA assay following the manufacturer's instructions (ZeptoMetrix, Buffalo, NY).

Immunoblotting. Cells were lysed in RIPA buffer for 10 min on ice before centrifugation 15 min 12000 RPM at $4^{\circ} \mathrm{C}$ and $40 \mu \mathrm{g}$ protein was typically loaded on the SDS tris-glycine gels. Electrophoresis was performed by 150 volt for $1 \mathrm{~h}$ and wet blotting $1 \mathrm{~h}$ at 100 volt or by semi-dry blotting for $7 \mathrm{~min}$, mixed range (Thermo-fisher). Membranes were blocked by $5 \%$ BSA TBS-TWEEN for $1 \mathrm{~h}$ and incubated with primary antibodies at $4{ }^{\circ} \mathrm{C}$ overnight before washed with TBS-TWEEN, incubated with secondary antibody hrp-goat-anti-mouse/rabbit (1:1000) for $1 \mathrm{~h}$ at RT. Then membranes were washed two times with TBS-TWEEN and one time with TBS before developed by pico/pico plus/femto chemiluminescent substrate (Thermo Fisher) and developed digitally by the use of digital developer ImageQuant LAS 4000 (GE Healthcare Life Sciences) or ChemidocTM MP Imaging system (Bio-Rad) using Image Lab 5.0 (Bio-Rad, 2013) for image analysis. Antibodies for immunblotting: Tax (Tab172, 1:100), HTLV-1 p24Gag (ABL inc., 1:1000), COXIV (Abcam, 1:2500), anti-HA (Cell Signaling Technologies, 1:1000), $\beta$-actin (Abcam, 1:1000), $\beta$-tubulin (Abcam, 1:500).

Orf-I sequencing. Orf-I sequencing was performed as described previously ${ }^{36}$ with slight modifications.

Approximately $1 \times 10^{6}$ cells were collected and DNA was extracted using QIAamp DNA Blood Mini Kit (Qiagen), according to manufacturer's instructions. DNA fragment covering orf-I was amplified by PCR using Platinum PCR SuperMix (Invitrogen) with primers (p12-F: 5'-CACCTCGCCTTCCAACTG-3', p30-R: $5^{\prime}$-GGAGTATTTGCGCATGGCC-3') and $300 \mathrm{ng}$ of genomic DNA. The PCR reaction was carried out using an Eppendorf Master Cycler gradient PCR machine, for 35 cycles of; $94^{\circ} \mathrm{C}$ for $30 \mathrm{sec}, 55^{\circ} \mathrm{C}$ for $30 \mathrm{sec}$, and $68^{\circ} \mathrm{C}$ for 
$50 \mathrm{sec}$. The PCR product was purified using Qiaquick PCR purification kit (Qiagen) and $50 \mathrm{ng}$ DNA together with 0.64 picomol of primer ( $5^{\prime}$-CTGGACAGGTGGCCAGTA- $\left.3^{\prime}\right)$ was used for sequencing. The Sanger sequencing was carried out at the CCR genomics core at NCI, NIH.

Jurkat-memCherry-orf-I cells. The pSDM-N26(p8)-HA or pSDM-G29S(p12)-HA lentiviral GFP expressing plasmid were cloned into pSDM101 ${ }^{81}$ (herafter pSDM) after PCR amplification (p12-PmeI-F: 5'-ATTAGTT TAAACGCCACCATGCTGTTTCGCCTTC- $3^{\prime}$ and p12-BamHI-R 5'- ATTAGGATCCCTAGAAGAGGAAA GCCGCGGC-3') of N26 and G29S from the pME18S p12deltaSL expression plasmid as previously described ${ }^{35,36}$, digested with PmeI and BamH1 restriction enzymes and re-cloned into the pmeI and BamH1 digested pSDM vector. All constructs were verified by sequencing. A $10 \mathrm{~cm}$ dish with $60-80 \%$ confluent $293 \mathrm{FT}$ cells was transfected using PEI transfection reagent (Polyscience Inc) where $400 \mu \mathrm{l}$ of DMEM without FBS was added $12 \mu \mathrm{g}$ pSDM, pSDM-N26(p8)-HA or pSDM-G29S(p12)-HA, $8 \mu \mathrm{g}$ of psPAX-2 (Packaging plasmid, Addgene) and $6 \mu \mathrm{g}$ pMD2.G (Env, Addgene). Further, $26 \mu \mathrm{l}$ PEI $(2 \mathrm{mg} / \mathrm{ml})$ was diluted in $400 \mu \mathrm{l}$ of DMEM without FBS before combined with the DNA solution, vortexed and incubated at room temperature for $5 \mathrm{~min}$ before added to the $10 \mathrm{~cm}$ dish with the 293FT cells in $10 \mathrm{ml}$ complete medium. The cells were then incubated for $8 \mathrm{~h}$ before the medium was replaced with $8 \mathrm{ml}$ fresh complete medium and cultured for another $48 \mathrm{~h}$.

The cell culture supernatant from the 293FT cells was centrifuged for $5 \mathrm{~min}$ at $1500 \mathrm{RPM}$ and then filtered through a $0.22 \mu \mathrm{m}$ filter. This was followed by centrifugation at $8000 \mathrm{RCF}$ (Eppendorf centrifuge $5418 \mathrm{R}$ ) for $3 \mathrm{~h}$ at $4^{\circ} \mathrm{C}$ and removal of all supernatant, except $20 \mu$. The concentrated virus was resuspended in $100 \mu \mathrm{l}$ of RPMI-1640 without FBS. The Jurkat-memCherry cells were centrifuged at $1200 \mathrm{RPM}$ for $5 \mathrm{~min}$, resuspended in the virus solution, incubated for $5 \mathrm{~min}$ at $37^{\circ} \mathrm{C}$ before centrifuged for $10 \mathrm{~min}$ at $800 \mathrm{RCF}$. Finally, the cells were resuspended in $1 \mathrm{ml}$ of complete medium in a 12 -well plate for $72 \mathrm{~h}$. Transduction efficiency was measured by flow cytometry (FACSCalibur, BD).

Generation and characterization of HTLV-1 primary human cells: CD4+ ${ }^{+}$-pAB-D26. Stable HTLV-1 producing 729.6 human lymphoblastoid B-cells were generated as previously described ${ }^{37}$. The $729-6$ $\mathrm{B}$-cell line infected with the $\mathrm{pAB}$ wild-type virus were maintained in RPMI 1640 with $10 \% \mathrm{FBS}$. Using negative selection beads (StemCell), CD4 ${ }^{+}$T-cells were isolated from healthy donors peripheral blood mononuclear cells. Stable HTLV-1 producing CD4 ${ }^{+}$T-cell lines were established by co-cultivation of donor uninfected primary HLA.A2+/CD4 ${ }^{+}$T-cells with lethally $\gamma$-irradiated $729.6-H T L V-1$ infected cells. T-cells were cultured in RPMI supplemented with $20 \%$ FBS and $100 \mathrm{U}$ of interleukin-2 for several months. Viral genomic sequences verified by sequencing of the ClaI-SalI fragment as described previously ${ }^{36}$.

Phenotyping of CD4 ${ }^{+}$HTLV-1 cells. CD4 ${ }^{+}-$pAB-D26 HTLV-1 cells, were stained with the antibodies anti-CD3 (Alexa Fluor 700), anti-CD4 (peri- dinin chlorophyll protein [PerCP]-Cy5.5), anti-CD8 (Qdot 655), anti-CD20 (Qdot 605), all obtained from BD Biosciences and additionally stained with LIVE/DEAD fixable aqua dead cell stain (Molecular Probes).

DNA extraction. CD4 ${ }^{+}$HTLV- 1 cells were submitted to genomic DNA extraction. Genomic DNA was isolated using a DNeasy blood and tissue kit (Qiagen). PCR amplification was performed with $100 \mathrm{ng}$ of DNA with the following primers gag-F1 (5-GGCCAAATCCTTTCC CGTAG-3) and gag-R1 (5'-GTTGTGGATTGTTGGCTTGG-3'), $\beta$-actin-F1 (5'-CGGTTGGCCTTGGGGTTCAGGGGG-3') and $\beta$-actin-R1 (5'-ATCGTGGGGCGCCCCAGGCACCA-3'). Correctly sized amplicons were identified by $1 \%$ agarose gel electrophoresis.

Quantitation of HTLV-1 proviral DNA. HTLV-1 proviral load was measured in CD4 ${ }^{+} \mathrm{HTLV}-1 \mathrm{~T}$ cells by quantitative realtime PCR using TaqMan probe, as described previously ${ }^{82}$ with slight modifications. Genomic DNA was extracted with QIAGEN blood mini kit (QIAGEN) and subjected to PCR. Copy number of HTLV-1 was measured with primers for $\mathrm{pX}$ region of HTLV-1. RNase P gene, detected with TaqMan RNase P Control Reagents Kit (Applied Biosystems), was used as the endogenous reference in multiplex reactions. The proviral load (\%) was shown as the copy number of HTLV-1 per 100 of copy number of RNase P gene.

Microscopy. The fluorescent microscope AxioObserver Z1, Delta Vision Elite wide-field deconvolution microscope and the LSM780 confocal microscope (Carl Zeiss, Inc, Thornwood, NY) were used. Alpha Plan Apochromat 63X/1.4 NA Oil DICIII and appropriate filter sets for AxioObserver Z1 and Alpha Plan Apochromat 63X/1.46 NA Oil. Lasers: $25 \mathrm{~mW}$ Argon 488, $20 \mathrm{~mW}$ Diode Laser $561 \mathrm{~nm}$ for LSM780. Images were analyzed by the ZEN 2012 software. For scanning electron microscopy, images were captured by Jeol JSM-7400F LEI $4.0 \mathrm{kV}$, x3000 (x3700 for D2) and WD $8.0 \mathrm{~mm}$. Figures were generated using Photoshop CS6 and Zen software (Carl Zeiss). For 3D construction ImageJ $1.51 \mathrm{k}$ (National Institutes of Health (NIH)) was used on Z-stacks ( $1 \mu \mathrm{m}$ slices) using default settings for the $3 \mathrm{D}$ project plugin, including brightest point as projection method with Y-axis rotation. Images were prepared using Adobe Photoshop CS6 and Adobe Illustrator CS6.

Statistical analysis. Unpaired t-test was performed to evaluate statistic significant changes. F-test was performed to verify that the individual variations were not significant. GraphPad Prism (Version 6.03) was used $(* p \leq 0.05, * * p \leq 0.01, * * * p \leq 0.001)$.

\section{References}

1. Gallo, R. C. The first human retrovirus. Sci Am 255, 88-98 (1986)

2. Gessain, A. \& Cassar, O. Epidemiological Aspects and World Distribution of HTLV-1 Infection. Front Microbiol 3, 388, https://doi. org/10.3389/fmicb.2012.00388 (2012). 
3. Poiesz, B. J. et al. Detection and isolation of type C retrovirus particles from fresh and cultured lymphocytes of a patient with cutaneous T-cell lymphoma. Proc Natl Acad Sci USA 77, 7415-7419 (1980).

4. Takatsuki, K. Discovery of adult T-cell leukemia. Retrovirology 2, 16 (2005).

5. Gessain, A. et al. Antibodies to human T-lymphotropic virus type-I in patients with tropical spastic paraparesis. Lancet 2, 407-410 (1985).

6. Osame, M. et al. HTLV-I associated myelopathy, a new clinical entity. Lancet 1, 1031-1032 (1986).

7. Kamoi, K. \& Mochizuki, M. HTLV-1 uveitis. Front Microbiol 3, 270, https://doi.org/10.3389/fmicb.2012.00270 (2012).

8. Nishioka, K. et al. Chronic inflammatory arthropathy associated with HTLV-I. Lancet 1, 441 (1989).

9. Eguchi, K. et al. Primary Sjogren's syndrome with antibodies to HTLV-I: clinical and laboratory features. Ann Rheum Dis 51, 769-776 (1992).

10. Morgan, O. S., Rodgers-Johnson, P., Mora, C. \& Char, G. HTLV-1 and polymyositis in Jamaica. Lancet 2, 1184-1187 (1989).

11. Alais, S., Mahieux, R. \& Dutartre, H. Viral Source-Independent High Susceptibility of Dendritic Cells to Human T-Cell Leukemia Virus Type 1 Infection Compared to That of T Lymphocytes. J Virol 89, 10580-10590, https://doi.org/10.1128/JVI.01799-15 (2015).

12. de Castro-Amarante, M. F. et al. Human T Cell Leukemia Virus Type 1 Infection of the Three Monocyte Subsets Contributes to Viral Burden in Humans. J Virol 90, 2195-2207, https://doi.org/10.1128/JVI.02735-15 (2015).

13. Hanon, E. et al. Fratricide among CD8(+) T lymphocytes naturally infected with human T cell lymphotropic virus type I. Immunity 13, 657-664 (2000).

14. Knight, S. C., Macatonia, S. E., Cruickshank, K., Rudge, P. \& Patterson, S. Dendritic cells in HIV-1 and HTLV-1 infection. Adv Exp Med Biol 329, 545-549 (1993).

15. Koyanagi, Y. et al. In vivo infection of human T-cell leukemia virus type I in non-T cells. Virology 196, 25-33 (1993).

16. Longo, D. L. et al. Isolation of HTLV-transformed B-lymphocyte clone from a patient with HTLV-associated adult T-cell leukaemia. Nature 310, 505-506 (1984).

17. Macatonia, S. E., Cruickshank, J. K., Rudge, P. \& Knight, S. C. Dendritic cells from patients with tropical spastic paraparesis are infected with HTLV-1 and stimulate autologous lymphocyte proliferation. AIDS Res Hum Retroviruses 8, 1699-1706, https://doi. org/10.1089/aid.1992.8.1699 (1992).

18. Mann, D. L. et al. Identification of the human T cell lymphoma virus in B cell lines established from patients with adult $\mathrm{T}$ cell leukemia. J Clin Invest 74, 56-62, https://doi.org/10.1172/JCI111418 (1984).

19. Nath, M. D., Ruscetti, F. W., Petrow-Sadowski, C. \& Jones, K. S. Regulation of the cell-surface expression of an HTLV-I binding protein in human T cells during immune activation. Blood 101, 3085-3092, https://doi.org/10.1182/blood-2002-07-2277 (2003).

20. Richardson, J. H., Edwards, A. J., Cruickshank, J. K., Rudge, P. \& Dalgleish, A. G. In vivo cellular tropism of human T-cell leukemia virus type 1. J Virol 64, 5682-5687 (1990).

21. Setoyama, M., Kerdel, F. A., Elgart, G., Kanzaki, T. \& Byrnes, J. J. Detection of HTLV-1 by polymerase chain reaction in situ hybridization in adult T-cell leukemia/lymphoma. Am J Pathol 152, 683-689 (1998).

22. Suzuki, M. et al. CD45RO expression on peripheral lymphocytes as a prognostic marker for adult T-cell leukemia. Leuk Lymphoma 28, 583-590, https://doi.org/10.3109/10428199809058367 (1998)

23. Watanabe, T. Adult T-cell leukemia: molecular basis for clonal expansion and transformation of HTLV-1-infected T cells. Blood 129, 1071-1081, https://doi.org/10.1182/blood-2016-09-692574 (2017)

24. Jones, K. S. et al. Molecular aspects of HTLV-1 entry: functional domains of the HTLV-1 surface subunit (SU) and their relationships to the entry receptors. Viruses 3, 794-810, https://doi.org/10.3390/v3060794 (2011).

25. Ghez, D., Lepelletier, Y., Jones, K. S., Pique, C. \& Hermine, O. Current concepts regarding the HTLV-1 receptor complex. Retrovirology 7, 99, https://doi.org/10.1186/1742-4690-7-99 (2010).

26. Jones, K. S., Petrow-Sadowski, C., Huang, Y. K., Bertolette, D. C. \& Ruscetti, F. W. Cell-free HTLV-1 infects dendritic cells leading to transmission and transformation of CD4(+) T cells. Nat Med 14, 429-436, https://doi.org/10.1038/nm1745 (2008).

27. Dutartre, H., Claviere, M., Journo, C. \& Mahieux, R. Cell-Free versus Cell-to-Cell Infection by Human Immunodeficiency Virus Type 1 and Human T-Lymphotropic Virus Type 1: Exploring the Link among Viral Source, Viral Trafficking, and Viral Replication. J Virol 90, 7607-7617, https://doi.org/10.1128/JVI.00407-16 (2016).

28. Pique, C. \& Jones, K. S. Pathways of cell-cell transmission of HTLV-1. Front Microbiol 3, 378, https://doi.org/10.3389/ fmicb.2012.00378 (2012).

29. Rizkallah, G. et al. Dendritic cell maturation, but not type I interferon exposure, restricts infection by HTLV-1, and viral transmission to T-cells. PLoS Pathog 13, e1006353, https://doi.org/10.1371/journal.ppat.1006353 (2017).

30. Igakura, T. et al. Spread of HTLV-I between lymphocytes by virus-induced polarization of the cytoskeleton. Science 299, 1713-1716, https://doi.org/10.1126/science.1080115 (2003).

31. Nejmeddine, M. \& Bangham, C. R. The HTLV-1 Virological Synapse. Viruses 2, 1427-1447, https://doi.org/10.3390/v2071427 (2010).

32. Pais-Correia, A. M. et al. Biofilm-like extracellular viral assemblies mediate HTLV-1 cell-to-cell transmission at virological synapses. Nat Med 16, 83-89, https://doi.org/10.1038/nm.2065 (2010).

33. Fukumoto, R. et al. In vivo genetic mutations define predominant functions of the human T-cell leukemia/lymphoma virus p12I protein. Blood 113, 3726-3734, https://doi.org/10.1182/blood-2008-04-146928 (2009).

34. Van Prooyen, N. et al. Human T-cell leukemia virus type $1 \mathrm{p} 8$ protein increases cellular conduits and virus transmission. Proc Natl Acad Sci USA 107, 20738-20743, https://doi.org/10.1073/pnas.1009635107 (2010).

35. Fukumoto, R. et al. Inhibition of T-cell receptor signal transduction and viral expression by the linker for activation of T cellsinteractingp12(I) protein of human T-cell leukemia/lymphoma virus type 1. J Virol 81, 9088-9099, https://doi.org/10.1128/ JVI.02703-06 (2007).

36. Pise-Masison, C. A. et al. Co-dependence of HTLV-1 p12 and p8 functions in virus persistence. PLoS Pathog 10, e1004454, https:// doi.org/10.1371/journal.ppat.1004454 (2014).

37. Valeri, V. W. et al. Requirement of the human T-cell leukemia virus $\mathrm{p} 12$ and $\mathrm{p} 30$ products for infectivity of human dendritic cells and macaques but not rabbits. Blood 116, 3809-3817, https://doi.org/10.1182/blood-2010-05-284141 (2010).

38. Donhauser, N., Heym, S. \& Thoma-Kress, A. K. Quantitating the Transfer of the HTLV-1p8 Protein Between T-Cells by Flow Cytometry. Front Microbiol 9, 400, https://doi.org/10.3389/fmicb.2018.00400 (2018).

39. Rustom, A., Saffrich, R., Markovic, I., Walther, P. \& Gerdes, H. H. Nanotubular highways for intercellular organelle transport. Science 303, 1007-1010, https://doi.org/10.1126/science.1093133 (2004).

40. Chauveau, A., Aucher, A., Eissmann, P., Vivier, E. \& Davis, D. M. Membrane nanotubes facilitate long-distance interactions between natural killer cells and target cells. Proc Natl Acad Sci USA 107, 5545-5550, https://doi.org/10.1073/pnas.0910074107 (2010).

41. Onfelt, B., Nedvetzki, S., Yanagi, K. \& Davis, D. M. Cutting edge: Membrane nanotubes connect immune cells. J Immunol 173, $1511-1513(2004)$

42. Osteikoetxea-Molnar, A. et al. The growth determinants and transport properties of tunneling nanotube networks between B lymphocytes. Cell Mol Life Sci, https://doi.org/10.1007/s00018-016-2233-y (2016).

43. Eugenin, E. A., Gaskill, P. J. \& Berman, J. W. Tunneling nanotubes (TNT) are induced by HIV-infection of macrophages: a potential mechanism for intercellular HIV trafficking. Cell Immunol 254, 142-148, https://doi.org/10.1016/j.cellimm.2008.08.005 (2009).

44. Hashimoto, M. et al. Potential Role of the Formation of Tunneling Nanotubes in HIV-1 Spread in Macrophages. J Immunol 196, 1832-1841, https://doi.org/10.4049/jimmunol.1500845 (2016). 
45. Okafo, G., Prevedel, L. \& Eugenin, E. Tunneling nanotubes (TNT) mediate long-range gap junctional communication: Implications for HIV cell to cell spread. Sci Rep 7, 16660, https://doi.org/10.1038/s41598-017-16600-1 (2017).

46. Panasiuk, M., Rychlowski, M., Derewonko, N. \& Bienkowska-Szewczyk, K. Tunneling nanotubes (TNT) as a novel route of cell-tocell spread of herpesviruses. J Virol, https://doi.org/10.1128/JVI.00090-18 (2018).

47. Roberts, K. L., Manicassamy, B. \& Lamb, R. A. Influenza A virus uses intercellular connections to spread to neighboring cells. J Virol 89, 1537-1549, https://doi.org/10.1128/JVI.03306-14 (2015).

48. Sowinski, S. et al. Membrane nanotubes physically connect $\mathrm{T}$ cells over long distances presenting a novel route for HIV-1 transmission. Nat Cell Biol 10, 211-219, https://doi.org/10.1038/ncb1682 (2008).

49. Omsland, M., Bruserud, O., Gjertsen, B. T. \& Andresen, V. Tunneling nanotube (TNT) formation is downregulated by cytarabine and NF-kappaB inhibition in acute myeloid leukemia (AML). Oncotarget 8, 7946-7963, https://doi.org/10.18632/oncotarget.13853 (2017).

50. Sowinski, S., Alakoskela, J. M., Jolly, C. \& Davis, D. M. Optimized methods for imaging membrane nanotubes between T cells and trafficking of HIV-1. Methods 53, 27-33, https://doi.org/10.1016/j.ymeth.2010.04.002 (2011).

51. Miyoshi, I. et al. Type C virus particles in a cord T-cell line derived by co-cultivating normal human cord leukocytes and human leukaemic T cells. Nature 294, 770-771 (1981).

52. Miyoshi, I. et al. Transformation of normal human cord lymphocytes by co-cultivation with a lethally irradiated human T-cell line carrying type C virus particles. Gan 72, 997-998 (1981).

53. Benard, M. et al. Structural and functional analysis of tunneling nanotubes (TnTs) using gCW STED and gconfocal approaches. Biol Cell 107, 419-425, https://doi.org/10.1111/boc.201500004 (2015).

54. Wittig, D. et al. Multi-level communication of human retinal pigment epithelial cells via tunneling nanotubes. PLoS One 7, e33195, https://doi.org/10.1371/journal.pone.0033195 (2012).

55. Tamamyan, G. et al. Frontline treatment of acute myeloid leukemia in adults. Crit Rev Oncol Hematol 110, 20-34, https://doi. org/10.1016/j.critrevonc.2016.12.004 (2017).

56. Spriggs, D., Griffin, J., Wisch, J. \& Kufe, D. Clinical pharmacology of low-dose cytosine arabinoside. Blood 65, 1087-1089 (1985).

57. Chan, J. K. \& Greene, W. C. Dynamic roles for NF-kappaB in HTLV-I and HIV-1 retroviral pathogenesis. Immunol Rev 246, 286-310, https://doi.org/10.1111/j.1600-065X.2012.01094.x (2012).

58. Currer, R. et al. HTLV tax: a fascinating multifunctional co-regulator of viral and cellular pathways. Front Microbiol 3, 406, https:// doi.org/10.3389/fmicb.2012.00406 (2012).

59. Nagata, K., Ohtani, K., Nakamura, M. \& Sugamura, K. Activation of endogenous c-fos proto-oncogene expression by human T-cell leukemia virus type I-encoded p40tax protein in the human T-cell line, Jurkat. J Virol 63, 3220-3226 (1989).

60. Hase, K. et al. M-Sec promotes membrane nanotube formation by interacting with Ral and the exocyst complex. Nat Cell Biol 11, 1427-1432, https://doi.org/10.1038/ncb1990 (2009).

61. Astier-Gin, T., Portail, J. P., Lafond, F. \& Guillemain, B. Identification of HTLV-I- or HTLV-II-producing cells by cocultivation with BHK-21 cells stably transfected with a LTR-lacZ gene construct. J Virol Methods 51, 19-29 (1995).

62. Hermine, O., Ramos, J. C. \& Tobinai, K. A Review of New Findings in Adult T-cell Leukemia-Lymphoma: A Focus on Current and Emerging Treatment Strategies. Adv Ther 35, 135-152, https://doi.org/10.1007/s12325-018-0658-4 (2018).

63. Jaworski, E. et al. Human T-lymphotropic virus type 1-infected cells secrete exosomes that contain Tax protein. J Biol Chem 289, 22284-22305, https://doi.org/10.1074/jbc.M114.549659 (2014).

64. D’Aloia, A. et al. RalGPS2 is involved in tunneling nanotubes formation in 5637 bladder cancer cells. Exp Cell Res, https://doi. org/10.1016/j.yexcr.2017.11.036 (2017).

65. Ariazi, J. et al. Tunneling Nanotubes and Gap Junctions-Their Role in Long-Range Intercellular Communication during Development, Health, and Disease Conditions. Front Mol Neurosci 10, 333, https://doi.org/10.3389/fnmol.2017.00333 (2017).

66. Burtey, A. et al. Intercellular transfer of transferrin receptor by a contact-, Rab8-dependent mechanism involving tunneling nanotubes. FASEB J 29, 4695-4712, https://doi.org/10.1096/fi.14-268615 (2015).

67. Desir, S. et al. Tunneling nanotube formation is stimulated by hypoxia in ovarian cancer cells. Oncotarget 7, 43150-43161, https:// doi.org/10.18632/oncotarget.9504 (2016).

68. Gousset, K. et al. Prions hijack tunnelling nanotubes for intercellular spread. Nat Cell Biol 11, 328-336, https://doi.org/10.1038/ ncb1841 (2009).

69. Pasquier, J. et al. Preferential transfer of mitochondria from endothelial to cancer cells through tunneling nanotubes modulates chemoresistance. J Transl Med 11, 94, https://doi.org/10.1186/1479-5876-11-94 (2013).

70. Saenz-de-Santa-Maria, I. et al. Control of long-distance cell-to-cell communication and autophagosome transfer in squamous cell carcinoma via tunneling nanotubes. Oncotarget 8, 20939-20960, https://doi.org/10.18632/oncotarget.15467 (2017).

71. Sherer, N. M. et al. Retroviruses can establish filopodial bridges for efficient cell-to-cell transmission. Nat Cell Biol 9, 310-315, https://doi.org/10.1038/ncb1544 (2007).

72. Hiraiwa, N., Hiraiwa, M. \& Kannagi, R. Human T-cell leukemia virus-1 encoded Tax protein transactivates alpha 1->3 fucosyltransferase Fuc-T VII, which synthesizes sialyl Lewis X, a selectin ligand expressed on adult T-cell leukemia cells. Biochem Biophys Res Commun 231, 183-186, https://doi.org/10.1006/bbrc.1997.6068 (1997).

73. Giam, C. Z. \& Semmes, O. J. HTLV-1 Infection and Adult T-Cell Leukemia/Lymphoma-A Tale of Two Proteins: Tax and HBZ. Viruses 8, https://doi.org/10.3390/v8060161 (2016).

74. Kataoka, K. et al. Integrated molecular analysis of adult T cell leukemia/lymphoma. Nat Genet 47, 1304-1315, https://doi. org/10.1038/ng.3415 (2015)

75. Bazarbachi, A. et al. Meta-analysis on the use of zidovudine and interferon-alfa in adult T-cell leukemia/lymphoma showing improved survival in the leukemic subtypes. J Clin Oncol 28, 4177-4183, https://doi.org/10.1200/JCO.2010.28.0669 (2010).

76. Dassouki, Z. et al. ATL response to arsenic/interferon therapy is triggered by SUMO/PML/RNF4-dependent Tax degradation. Blood 125, 474-482, https://doi.org/10.1182/blood-2014-04-572750 (2015)

77. Iwanaga, M. et al. Human T-cell leukemia virus type I (HTLV-1) proviral load and disease progression in asymptomatic HTLV-1 carriers: a nationwide prospective study in Japan. Blood 116, 1211-1219, https://doi.org/10.1182/blood-2009-12-257410 (2010).

78. Nagai, M. et al. Analysis of HTLV-I proviral load in 202 HAM/TSP patients and 243 asymptomatic HTLV-I carriers: high proviral load strongly predisposes to HAM/TSP. J Neurovirol 4, 586-593 (1998).

79. Erikstein, B. S. et al. Cellular stress induced by resazurin leads to autophagy and cell death via production of reactive oxygen species and mitochondrial impairment. J Cell Biochem 111, 574-584, https://doi.org/10.1002/jcb.22741 (2010).

80. Lu, H. et al. Tax relieves transcriptional repression by promoting histone deacetylase 1 release from the human T-cell leukemia virus type 1 long terminal repeat. J Virol 78, 6735-6743, https://doi.org/10.1128/JVI.78.13.6735-6743.2004 (2004).

81. Chevalier, S. A. et al. The transcription profile of Tax-3 is more similar to Tax-1 than Tax-2: insights into HTLV-3 potential leukemogenic properties. PLoS One 7, e41003, https://doi.org/10.1371/journal.pone.0041003 (2012).

82. Tanaka, G. et al. The clonal expansion of human T lymphotropic virus type 1-infected T cells: a comparison between seroconverters and long-term carriers. J Infect Dis 191, 1140-1147, https://doi.org/10.1086/428625 (2005). 


\section{Acknowledgements}

Confocal microscopy was performed at the NCI Core Fluorescence Imaging Facility and we are grateful for the help from Dr. Tatiana S. Karpova. The scanning electron microscopy imaging was performed at the Molecular Imaging Center (MIC) and was thus supported by the Department of Biomedicine and the Faculty of Medicine and Dentistry, at the University of Bergen, and its partners. We are grateful for the assistance from Endy Spriet and Anne Karin Nyhaug for assistance in SEM samples preparation. We thank André Sulen for help with the sorting of THP-1-memGFP and Jurkat-memCherry positive cells. This work was supported by: the Intramural Research Program of the National Institutes of Health, National Cancer Institute, Center for Cancer Research, and federal funds from the National Cancer Institute, National Institutes of Health (M.O., C.P.M., D.F., C.F., R.P.W., G.F.), Bergen Research Foundation, University of Bergen (VA), University of Bergen (M.O.), Travel grants from: MedIm and research on cancer diseases, University of Bergen and The Norwegian Society of Engineers and Technologists (NITO), The Norwegian Institute of Biomedical science (MO), Norwegian Cancer Society with Solveig \& Ole Lunds Legacy and Øyvinn Mølbach-Petersens Fond for Clinical Research (Grant no. 104712, 145268, 145269 and 163424) (BTG).

\section{Author Contributions}

M.O. and V.A.: designed and performed research, analyzed data and wrote the paper. R.W.P. performed p19 Gag assay. C.P.M., D.F. and C.F. sequenced orf-I and generated lentiviral vectors, designed research, analyzed data and wrote the paper. V.G.: performed p19 Gag assay and generated the CD4 ${ }^{+}$D26 primary cells and verified them. B.T.G. and G.F.: designed research, analyzed data and wrote the paper. All authors reviewed the manuscript.

\section{Additional Information}

Supplementary information accompanies this paper at https://doi.org/10.1038/s41598-018-29391-w.

Competing Interests: The authors declare no competing interests.

Publisher's note: Springer Nature remains neutral with regard to jurisdictional claims in published maps and institutional affiliations.

(c) (i) Open Access This article is licensed under a Creative Commons Attribution 4.0 International License, which permits use, sharing, adaptation, distribution and reproduction in any medium or format, as long as you give appropriate credit to the original author(s) and the source, provide a link to the Creative Commons license, and indicate if changes were made. The images or other third party material in this article are included in the article's Creative Commons license, unless indicated otherwise in a credit line to the material. If material is not included in the article's Creative Commons license and your intended use is not permitted by statutory regulation or exceeds the permitted use, you will need to obtain permission directly from the copyright holder. To view a copy of this license, visit http://creativecommons.org/licenses/by/4.0/.

(C) The Author(s) 2018 